
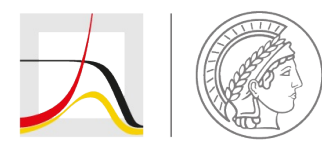

MAX PLANCK INSTITUTE

FOR DEMOGRAPHIC RESEARCH

Konrad-Zuse-Strasse 1 · D-18057 Rostock · Germany · Tel +49 (0) 3812081 - 0 · Fax +49 (0) 3812081 - $202 \cdot$ www.demogr.mpg.de

MPIDR Working Paper WP 2022-006 I February 2022

https://doi.org/10.4054/MPIDR-WP-2022-006

\title{
The prospective power of personality for childbearing: a longitudinal study based on data from Germany
}

Steffen Peters I peters@demogr.mpg.de

This working paper has been approved for release by: Maarten J. Bijlsma (bijlsma@demogr.mpg.de),

Deputy Head of the Laboratory of Population Health.

(c) Copyright is held by the authors.

Working papers of the Max Planck Institute for Demographic Research receive only limited review. Views or opinions expressed in working papers are attributable to the authors and do not necessarily reflect those of the Institute. 


\title{
The prospective power of personality for childbearing: A longitudinal study based on data from Germany.
}

\author{
Steffen Peters ${ }^{1,2}$ \\ 1Max Planck Institute for Demographic Research \\ 2Stockholm University \\ Keywords: Fertility, Personality, Five Factor Model, Timing of Childbirth
}

\section{Abstract}

\section{BACKGROUND}

The link between personality and fertility is relatively underexplored. Moreover, there are only a few studies focusing on the prospective association between personality and childbearing. However, none of these considers the Five Factor Model (FFM), which is the most widely accepted measurement of personality.

\section{OBJECTIVE}

The present study fills this gap by examining the prospective associations between the FFM and the timing of the first and the second childbirth in Germany.

\section{METHODS}

Analyses are based on recent data (2005-2017) from the Socio-econom ic Panel Study. Cox Proportional Hazard Models were applied. 


\section{RESULTS}

Findings demonstrate that personality traits are associated with fertility. Extraversion is positively linked with first, but negatively associated with second childbirths. These findings are mainly driven by males. Agreeableness is positively linked with first childbirth within the total sam ple. Again, this correlation is mainlybased on the findings am ong men who also reveal positive associations between agreeableness and second childbirths. With respect to women, no significantcorrelations between personality and first childbirths can be found. However, the timing of receiving a second child is negatively associated with conscientiousness and neuroticism.

\section{CONTRIBUTION}

My study complements the current understanding of the personality-fertility association by exploring the impact of personality trait scores from the FFM on subsequent fertility behavior. However, further research is needed to better understand the path from personality to childbearing; the mechanisms through which personality affects fertility; and how these links differ across cultures, among higher parities, or regarding births after re-partnering.

\section{Introduction}

Previous research has shown that personality is correlated with family formation processes. It has, for example, been reported that extraversion increases the number of social contacts, which affects the chances of falling in love; whereas shyness is associated with lower chances of starting rom antic relationships (Asendorpf \& Wilpers 1998). Moreover, conscientiousness and extraversion appear to be correlated with a 
higher probability of getting married (Jokela et al. 2011; Lundberg 2012), and - with respect to extraversion - with a younger age at first marriage (Jokela et al. 2011); whereas openness and risk tolerance have been linked to the opposite outcomes (Jokela et al. 2011; Lundberg 2012; Schmidt2008). Additionally, studies have found that certain facets such as openness are linked with higher probabilities of partnership dissolution (Lundberg 2012; Solom on \& Jackson 2014). Furthermore, Soderm ans and colleagues (2017) found that neurotic individuals tend to enter multiple subsequent relationships after divorce, whereas conscientious people do not. These results suggest that certain personality factors are correlated with partnership stability (Sodermans et al. 2017). However, most of the correlations reported above have been shown to vary between genders (e.g. Jokela et al. 2011; Lundberg 2012; Sodermans et al. 2017). Although previous research has found an association between personality and family formation, the association between personality and childbearing is less explored.

Research on the personality-fertility link conducted by Markus Jokela and colleagues has found that fertility outcomes are positively connected with leadership skills (Jokela \& Keltikangas-Järvinen 2009), extraversion (Alvergne et al. 2010; Jokela 2012; Jokela et al. 2011), and sociability (Jokela et al. 2009). Other traits such as openness to new experiences are negatively associated with fertility (Jokela 2012; Jokela et al. 2011). In the German context, previous research has shown that high self-esteem is linked with higher fertility, and that high levels of male aggressiveness are associated with lower fertility (Hutteman et al. 2013). In addition, research has indicated that correlations between personality and fertility differ between sexes; e.g., that extraversion is positively associated with fertility among males, but less so among fem ales (Allen 2019; Skirbekk \& Blekesaune 2014). 
The data situation in the past allowed researchers to focus on single facets of personality only, or to measure personality at relatively high ages (mean age appr. 35 or higher) and, therefore, after the majority of births have already taken place (Avison \& Furnham 2015; Skirbekk \& Blekesaune 2014; Tavares 2016). Additionally, most surveys did not collect personality information before the early 2000 s. For instance, the Socio-economic Panel Study (SOEP), the Health and Retirement Study (HRS), and the British Household Panel Survey (BHPS) did not start collecting personality information until 2005 (SOEP, BHPS) or 2006 (HRS). Only a few earlier surveys, such as the Hawaii Personality and Health Cohort (1959-1967) or the Project Talent (1960), included personality inform ation.

The present study contributes substantially to the existing research on personality and fertility outcomes. To my knowledge, this is the first study to exam ine the prospective association between personality traits from the Five Factor Model (FFM) and fertility. The prospective design allows me to explain childbearing based on personality and avoid reverse causality. Previous studies show that personality may change after childbearing (Bleidorn et al. 2018; Jokela et al. 2009). Therefore, it is important to collect personality information before the birth of children and apply prospective approaches. With respect to different types of measuring personality, the FFM has been shown to be the mostreliable and robust approach (Ashton \& Lee 2005; Goldberg 1993; McCrae \& Costa 1987; McCrae \& John 1992). Thus, the association between this model and fertility is of particular interest. Previous research has missed to explore this correlation to a large extent. Some studies use the FFM for examining fertility outcomes but only consider cross-sectional data (Alvergne et al. 2010; Avison \& Furnham 2015). Other analyses are based on longitudinal data but use the FFM measured at relatively high ages (Jokela et al. 2011; Skirbekk \& Blekesaune 2014; Tavares 2016). Studies that explore the personality-fertility link by prospective designs 
do not use the FFM as personality measurement (Huttem an et al. 2013; Jokela et al. 2009; Jokela \& Keltikangas-Järvinen 2009).

My study overcomes these weaknesses of previous studies by examining the prospective association between personality factors and the timing of fertility using the most reliable personality measure, namely the FFM (Ashton \& Lee 2005; Goldberg 1993). I run Cox Proportional Hazard (Cox PH) regressions using longitudinal data from Germany (GSOEP) from 2005-2017. In order to obtain deeper insights into the personality-fertility link, I study this association for first and second childbirths in Germany as well as separated by gender. Regarding personality dimensions, it is important to keep in mind that they do not exist independentfrom each other but should rather be considered in com binations. For this reason, I further explore the personalityfertility link by running separate analyses using personality clusters. Although the focus shall lie on the timing of childbearing over life course, I also examine the association between personality facets and number of children at ages 40 or later.

\section{Theoretical Background}

Personality is, by definition, the collection of thoughts, feelings, and behaviors that form an individual's distinctive character (Uher 2017). The individual combination of these facets accompanies people through various situations in their daily lives. One of the fundam ental decisions people make over their life course is whether - and, if so, when - to have a child. When planning a pregnancy, an individual's personality will play an important role, as many factors need to be considered, such as characteristics from the person's social network (Bernardi \& Klaerner 2014), or the person's work situation (Kaufman \& Bernhardt 2012). How people balance these factors depends very much 
on their individual personality. In the following section, I review previous research examining how personality traits may be associated with childbearing.

\section{Five Factor Model and Fertility}

In psychological research, one particular model has been widely accepted as the most robust and reliable: namely, the Big Five Inventory (BFI), from which the Five Factor Model (FFM) has been developed (Ashton \& Lee 2005). A helpful overview of the BFI history can be found in Goldberg (1993). The FFM consists of agreeableness, conscientiousness, extraversion, neuroticism, and openness to experience (McCrae \& Costa 1987). Each of these dimensions covers a range of specific personality facets.

\section{Agreeableness}

Agreeableness is the tendency towards being forgiving, sympathetic, friendly, and warm. This trait can be connected with fertility via various mechanisms. People report that personality facets like kindness and considerateness are among the characteristics they most desire in potential partners (Buss \& Barnes 1986; Li et al. 2002). Additionally, agreeableness has been found to be positively associated with partnership quality (Holland \& Roism an 2008) and relationship satisfaction (Orth 2013). Furthermore, it has been shown that less agreeable individuals tend to be more ambivalent about having children (Pinquart et al. 2008), which could lead to lower fertility. In line with this finding, nurturance (being sympathetic, helpful) and affiliation (enjoying time with other people, willing to make friends) - both correlated with agreeableness (Costa Jr. et al. 1991) - have been found to be positively associated 
with the motivation to have a child (Miller 1992). Therefore, in the present study, I expect to find a positive association between agreeableness and fertility.

Previous findings supportthis expectation. It has, for exam ple, been shown that women with higher scores on agreeableness give birth to more children (Jokela et al. 2011), and are less likely to be childless (Tavares 2016); whereas these associations have not been found among men (Jokela 2012; Jokela et al. 2011). However, there is evidence that higher scores on agreeableness are associated with having children earlier in the life course among m en, but not among women (Jokela et al. 2011).

\section{Conscientiousness}

Conscientious individuals are relatively well-organized, thorough, reliable, and hardworking. Some studies have suggested that conscientiousness has a negative impact on career outcomes (Boudreau et al. 2001; Bozionelos 2004; Gelissen \& de Graaf 2006; Roberts \& Bogg 2004). This could be explained by the focus of conscientiousness being on family rather than on work life (Elder Jr. \& Maclnnis 1983). Furthermore, conscientious individuals tend to reveal higher levels of relationship quality (Holland \& Roisman 2008) and happiness (Orth 2013), as well as lower risks of

infidelity (Orzeck \& Lung 2005). Thus, conscientiousness might be positively related to fertility (Jokela \& Keltikangas-Järvinen 2009). On the other hand, conscientious individuals tend to clearly define their career goals (Judge \& llies 2002), and feel more satisfied with their job (Sutin et al. 2009). Thus, experiencing conflicts between work and family could cause more career-oriented women to have lower fertility, or to postpone having children (Blossfeld \& Huinink 1991; Gustafsson 2001; Skirbekk 2008; 
Van Bavel 2010). Therefore, the hypothesized direction of the association between conscientiousness and fertility appears to be ambiguous.

Previous research provides stronger evidence for a negative correlation between this trait and fertility. Conscientious individuals, and particularly females, tend to have fewer children (Jokela et al. 2011; Skirbekk \& Blekesaune 2014). In line with this finding, it has been reported that conscientious women have a lower likelihood of having a first child, but that conscientious men do not (Jokela et al. 2011).

\section{Extraversion}

Extraversion is defined as being sociable, talkative, active, and dominant. Extraverted people might have higher fertility because they have greater chances of establishing larger social networks with closer relationships (Neyer \& Asendorpf 2001; Schmitt and Shackelford 2008). In line with this assum ption, it has been shown that extraversion is positively associated with the number of sex partners a person has over time (Allen \& Desille 2017; J. D. Miller et al. 2004; Nettle 2005, 2006; Schmitt 2004). Furthermore, being highly extraverted has been linked to a lower age at first marriage (Jokela et al. 2011), as well as a higher probability of being in a higher order marriage (Nettle 2005). High levels of extraversion have also been linked to having fewer difficulties with decision-making (Germeijs \& Verschueren 2011), which could affect decisions regarding childbearing. More extraverted individuals report higher levels of relationship quality (Holland \& Roisman 2008; Orth 2013), which could increase their partnership stability, and their fertility. Consequently, in the present analysis, I expect to find a positive correlation between extraversion and fertility. 
According to previous studies, am ong all personality traits of the FFM, extraversion has the strongest associations with sexual and fertility behavior (Allen 2019). High scores on this personality trait have been linked to a higher probability of having a first child (Jokela et al. 2011), earlier childbearing (Jokela et al. 2011; Tavares 2016), and lower rates of childlessness (Avison \& Furnham 2015) for both sexes. However, previous research also reveals stronger extraversion associations with fertility among males. It has, for example, been shown that extraversion is positively linked with reproductive behavior particularly among men (Allen 2019; Jokela et al. 2011; Skirbekk \& Blekesaune 2014).

\section{Neuroticism}

Neurotic people tend to be nervous, emotionally unstable, insecure, and moody. Higher scores on neuroticism have been negatively linked with relationship quality (Donnellan et al. 2004) and satisfaction (Fisher \& McNulty 2008; Karney \& Bradbury 1997; Malouff et al. 2010; McNulty 2008). More neurotic individuals have higher depression scores (Gershuny \& Sher 1998). They tend to worry a lot about their partnership and might decide to not have a child since parenthood could be experienced as a burden for the relationship (Lillard \& Waite 1993). Conversely, neurotic individuals may choose to have children to improve their own (life) stability in the future (Friedman et al. 1994; Johns et al. 2011). In general, therefore, previous findings are contradictory.

This ambiguousness can also be found in fertility research. On the one hand, researchers have found negative correlations between neuroticis $m$ and the probability of having children for both sexes (Jokela 2012). In line with these findings, it has been 
shown that more neurotic women have fewer children over the life course (Jokela et al. 2011). On the other hand, it has been reported that females with higher neuroticism scores tend to enter parenthood earlier in the life course (Jokela et al. 2011; Tavares 2016).

\section{Openness to new experiences}

People who are open to experiences tend to be creative, imaginative, curious, and broad-minded. This trait is associated with higher education and cognitive functioning (Wainwright et al. 2008), both of which are negatively linked with fertility outcomes (Hopcroft 2006; Retherford \& Sewell 1989; Skirbekk 2008). Furthermore, higher openness scores are associated with a lower risk of early sex debut and a lower num ber of unprotected sex acts (Miller et al. 2004). Additionally, openness is negatively correlated with traditional attitudes (McCrae 1996; Van Hiel \& Mervielde 2004). These values are positively linked with higher fertility (Holton et al. 2009; Kaufman2000; Puur et al. 2008). Another mechanism through which openness can be connected with fertility is marital behavior. Jokela and colleagues (2011) found that openness tends to delay first marriage and reduce the probability of first marriage, which could reduce fertility. It has also been shown that higher openness scores are associated with a lower risk of early childbearing (Miller et al. 2004) and a higher risk of unfaithfulness (Orzeck \& Lung 2005). Therefore, in this study, I expect to find a negative association between openness and fertility.

Previous studies support this expectation. Having a higher openness score has been found to delay the first childbirth, particularly among women (Miller et al. 2004; Jokela et al.2011; Tavares 2016); to decrease the probability of having children for both sexes 
(Jokela 2012; Jokela et al. 2011); and to reduce the number of children for both sexes (Jokela et al. 2011), or only am ong males (Skirbekk \& Blekesaune 2014).

This brief overview of previous research could lead the reader to conclude that the correlation between the FFM and fertility is well understood. However, these previous studies have fundamental weaknesses that do not allow for comprehensive conclusions about this association. One of these weaknesses has been the use of cross-sectional data (Alvergne, Jokela, and Lummaa 2010; Avison \& Furnham 2015). Other studies based on longitudinal data had another key lim itation: they collected data on personality at on average relatively high ages, i.e. after most of fertility has already taken place (Jokela 2012; Jokela et al. 2011; Skirbekk \& Blekesaune 2014; Tavares 2016). This approach is problematic, as it does not account for the possibility that an individual's personality might change after having children. For instance, it has been shown that emotionality may increase after childbearing (Jokela et al. 2009). Therefore, analyses using personality information from relatively high ages face problems of reverse causality. This study builds on the strengths of previous studies, while overcoming most of their weaknesses. Previous research indicates parity and gender differences in the association between personality traits and fertility, and the analyses in my study were therefore conducted separately by birth parity (first and second childbirth) and by gender.

Previous studies argue that personality characteristics should not be considered independently from each other since an individual's overall personality emerges through the combination of different personality factors (Sava \& Popa 2011). Therefore, additional analyses using personality types instead of separate personality traits were run to exam ine potential correlations between personality trait combinations and fertility. Personality types were created based on K-means clustering procedure, 
as suggested by previous studies (Cragar et al. 2005; Holden et al. 2006; Sava \& Popa 2011).

Previous research has revealed the personality-fertility link using fertility timing as outcome. However, some studies have also indicated that personality traits are associated with completed fertility, i.e. the number of children (Jokela et al. 2011; Skirbekk \& Blekesaune 2014). Therefore, I consider this fertility outcome in additional analyses as well. However, it shall not be the particular focus of my study since the prospective association between personality and completed fertility can not be explored based on the data that I use.

\section{Data and Methods}

\section{SOEP Data}

This study uses data from the German Socio-Economic Panel Study (SOEP). The SOEP is the largest multidisciplinary follow-up survey in Germany regarding the num ber of participants. It is conducted by the German Institute for Economic Research (DIW), and provides information about German households and their members since 1984. Each year, approximately 30,000 individuals from around 14,000 households participate in this study (Britzke \& Schupp 2018). In an effort to achieve greater representativeness, a number of subsamples and refreshments have been implemented over time. For instance, East Germans were included starting in 1990 in order to represent the country's total population after German reunification (Goebel et al. 2019). More details on all of the subsamples of the SOEP and their sizes can be found in Siegers, Belcheva, and Silbermann (2019). The SOEP provides data on a range of topics, including household composition, employment, and educational 
history; as well as on health and subjective indicators, like personal attitudes, and selfreported personality (Goebel et al. 2019).

\section{Study Design}

The present study focuses on the link between personality traits and the transition to the first and the second childbirth. The SOEP provides inform ation on a monthly basis about childbirths and birth parity. Therefore, the data allow me to look at the first and the second childbirth separately. Analyses of higher birth orders were conducted as well, but are not shown here because the confidence intervals were relatively large due to the very low number of such events over time. Therefore, two study sam ples were obtained. The first sample is used to examine the transition from being childless to (potentially) having a first child. It consists of individuals who had not entered parenthood before the first time the personality information was collected. Therefore, all respondents at risk must have been childless in 2005 (first wave including personality items), although they could have entered the study at a later point in time; e.g., in 2009, when the SOEP collected personality inform ation for the second time. These individuals were followed until their first childbirth or the end of the study (after reaching 2017 or dropping out for any reason) - whichever came first. The second sam ple is used to study the transition to the second childbirth. The respondents in this sample are those who were considered at risk of having a second child nine months after the first childbirth, and for whom personality inform ation is available. This sample includes all respondents who had a first child before 2005 , or who had their first child during the study period, and were followed thereafter. As with the first sample, the individuals in the second sample were followed until their second childbirth or the end of the study. Both samples were right-censored for two reasons. First, age 50 is assumed to mark the end of fecundability for women, based on an international 
comparison of the mean ages at menopause (Thom as et al. 2001). While men are not subject to this biological restriction, having a child after age 50 was very rare among the men in this sample. Therefore, observations for both females and males over 50 years of age were excluded. Furthermore, the data were right-censored, since not all participants gave birth to a first or a second child by the end of the study. The applied Cox Proportional Hazards (Cox $\mathrm{PH})$ model could capture the problem of rightcensoring as well as left-truncation, which occurred when individuals had a first or a second childbirth before the onset of the study, and were therefore excluded from the analyses.

Personality-related information has been available every four years since 2005. Since personality served as a predictor in this study, the childbirths had to have taken place after the personality information had been collected. Therefore, first childbirths before 2005 were not considered in the analysis on the age at first childbirth. Similarly, the individuals at risk of having a second childbirth were included in the analysis only if personality information was available for them. Personality values could change when new information was collected, but they were assumed to remain constant for the time between two observations of personality. This approach is in line with previous literature showing that personality remains relatively stable over short time intervals (Ardelt 2000; Hopwood \& Bleidorn 2018; Lucas \& Donnellan 2011).

\section{Personality Measure}

The SOEP contains 15 items belonging to the FFM personality traits. The adjectives rude (reversed), forgiving, and kind reflect the trait "agreeableness"; $(A)$ whereas thorough, lazy (reversed), and efficient reflect the characteristic "conscientiousness" 
(C). Talkative, sociable, and reserved (reversed) can be linked to "extraversion"; (E) and worrying, nervous, and relaxed (reversed) are associated with "neuroticism" (N). The assessment of "openness to new experiences" $(O)$ is based on the adjectives original, valuing, and imaginative. Factor analyses for my sample suggest that the single facets belong to the personality traits as listed. These analyses revealed reasonable rotated factor loadings (A: 0.35-0.58; C: 0.47-0.68; E: 0.60-0.67; N: 0.540.63; O: 0.42-0.55). The original version of the FFM covers more than these 15 items. However, previous research has shown that this short version can still be considered representative of the FFM (Boyce et al. 2016; Donnellan \& Lucas 2008). Participants could answer the item "I am som ebody who is ..." by using a Likert scale ranging from one (not applicable at all) to seven (completely applicable). Missing values were excluded from these analyses. Thus, the study samples only contained observations with information on all three trait-specific items for each personality factor. In this case, the scores of these facets were summed up, and the mean was calculated for the respective individual and year. The mean values could range from one (trait does not suit the respondent at all) to seven (trait fits completely). Eventually, all of the personality trait variables were standardized (mean=0, standard deviation=1). Cronbach's Alpha was used to measure the internal consistency of personality traits over time. Given that the Alpha depended on the number of tested items (Sijtsma2009; Tavakol \& Dennick 2011) and the SOEP only provided three items per trait, the relatively low values of some of the facets were reasonable (A: $0.49 ; C: 0.61 ; E: 0.73$; N: 0.64; O: 0.60). Additionally, the Intraclass Correlation Coefficients (ICC) were calculated to check the reliability of the personality measures over time. The results indicate that the coefficients were above 0.5 (A: 0.53; C: 0.55; $\mathrm{E}: 0.66 ; \mathrm{N}: 0.59$; O: 0.60), which can be interpreted as a moderate level of consistency (Koo \& Li 2016). 
Regarding additional analyses using personality clusters, several solutions based on K-means clustering procedure were examined. Figures A1-A3 in the Appendix reveal the mean values of personality traits within each personality cluster in the 3-, 4-, and 5-cluster-solution. It can be seen that some clusters consist of people with on average higher personality trait scores (e.g. cluster 2 in the 4-cluster-solution) whereas other types were clustered according to other combinations. For instance, individuals in cluster 3 (4-cluster-solution) reveal average scores on extraversion, neuroticism, and openness. However, they score on average much lower on agreeableness and conscientiousness. As previous research indicates, personality clusters do not necessarily have to be similar across studies (e.g. Holden et al. 2006; Sava \& Popa 2011). More helpful information on construct validity of personality clusters can be found in Holden et al. (2006), or with respect to external validity in Sava and Popa (2011).

\section{Control Variables}

Gender ("Female", "Male") was included as a time-independent covariate, and as a stratification factor based on inconsistent findings from previous research. Observations with missing values on gender or any other covariate were excluded. Since age was the time scale of these analyses, a constant age-related covariate was included in the models: the year of birth. Previous research has shown that personality can change, particularly at younger ages (Hopwood \& Bleidorn 2018; Specht et al. 2011). Among most people, a process of maturation - i.e., of increasing conscientiousness and agreeableness, as well as decreasing neuroticism - can be observed with age (Borghuis et al. 2017). Therefore, controlling for the birth year as an age measure can broaden the knowledge about the personality-fertility link. 
Additionally, numerous studies have reported a link between education and fertility. Highly educated individuals tend to have lower fertility (Sobotka et al. 2017) and to postpone childbirths (Monstad et al. 2008). Furthermore, education appears to be associated with personality (Meyer et al. 2019; Sutin et al. 2017). Previous research has demonstrated the prospective association between personality and educational attainment, and that this association is stronger than the reverse relationship. Therefore, education - measured in years (centered around 13 years of education) and enrolment status - serves as a mediator for the link between personality and fertility (Sutin et al. 2017). A similar picture can be drawn for the association between personality and civil (relationship) status. Personality can predict relationship status, but partnerships do not change personality much (Neyer \& Asendorpf 2001). However, the connection between divorce and personality is unclear (Bleidorn et al. 2018). Regarding fertility, the role of partnership status is well understood (Balbo et al. 2013): fertility is higher for married than for cohabiting couples (Baizán et al. 2003; Brien et al. 1999; Spéder \& Kapitány 2009). Consequently, civil status ("Single", "Cohabited", "Married", "Divorced/Widowed") is included as another mediator in these analyses.

Income has been shown to have strong negative associations with fertility (Bar et al. 2018; Córdoba \& Ripoll 2016). However, there is evidence indicating that higher income groups have increased their fertility in recent decades. This means that this correlation might have flattened instead of following a linear trend (Bar et al. 2018). Consequently, income (standardized logarithm of individual gross income in previous year) is included as a time-varying covariate. Further analyses using household income instead of individual income revealed that results are not affected heavily by using one indicator or the other. 
Recent research has pointed to the potential influence of familybackground on fertility. Thus, ignoring family background can bias the results (Kramarz, Skans, and Rosenqvist 2019). Family background includes the parents' education (Chen 2016). For this reason, the highest maternal and paternal school degree ("No degree", "Secondary school degree", "Intermediate school degree", "Technical or upper secondary school degree", and "Other degree") are included in the analysis. The associations between further family-related inform ation (parental religiosity, num ber of own siblings) and fertility were checked but not listed, since most of them were not statistically significant, and the personality trait coefficients did not change much.

At the starting point of this study (2005), the fertility rates in the former East Germany were lower than those in the former West Germany (Destatis 2020). Since 2005, the fertility levels in some states of the former East Germany have exceeded those in several states of the former West Germany. Over the past few years, the fertility levels of the two regions have converged (Destatis 2019). Consequently, region has been included in the present analysis, although the personality traits of East and West Germans do not seem to differ (Schimmack et al. 2008).

\section{Statistical Methods}

Since the presented research question deals with time to birth, time-to-event (eventhistory) analyses were run. The Cox Proportional Hazard Model (Cox PH) is one of the most prom inent methods within the field of event-history analyses. The Cox PH model does not make any assumptions about the shape of the baseline hazard function, i.e. the hazard risk of experiencing the event may increase, decrease or remain constant over specific time periods. Equation (1) represents the model of the present analyses: 


$$
\begin{aligned}
& h\left(t \mid X_{1}, \ldots, X_{p}\right)=h_{0}(t) * \exp \left(\beta_{0}+\beta_{1} \text { Agree }_{i}+\beta_{2} \text { Conscient }_{i}+\right. \\
& \beta_{3} \text { Extra }_{i}+\beta_{4} \text { Neuro }_{i}+\beta_{5} \text { Open }_{i}+\beta_{6} \text { Gender }_{i}+ \\
& \beta_{7} \text { AgeBaseline }_{i}+\beta_{8} \text { YearsEdu }_{i}+\beta_{9} \text { EnrolStat }_{i}+ \\
& \beta_{10} \text { CivilStat }_{i}+\beta_{11} \text { logIncome }_{i}+\beta_{12} \text { EduMom }_{i}+\beta_{13} \text { EduDad }_{i}+ \\
& \left.\beta_{14} \text { Region }_{i}\right)+\varepsilon_{i}
\end{aligned}
$$

The expression $h\left(t \mid X_{1}, \ldots, X_{p}\right)$ represents the hazard rate for each respondent depending on time point $t$ and vectors of considered covariates $X_{1}, \ldots, X_{p}$. This rate is the product of the baseline hazard $h_{0}(t)$ and the exponentiated sum of covariate terms, where $\beta_{0}$ is the estimated intercept and $\beta_{1} \ldots \beta_{14}$ are the estimated coefficients of the covariates. The expression $\varepsilon_{i}$ represents the error term for each individual $i$. The underlying time scale of this model is age in months (until first childbirth), and time in months since nine months after first child (until second childbirth), respectively. Individuals are followed until they experience the event or drop out of the study, or until the end of the study in 2017. Since SOEP is a householdbased panel, this analysis adjusts for cluster effects coming from households using robust standard errors. One of the key assumptions of the model is proportionality. Statistical and graphical tests using Schoenfeld residuals reveal no violation of the proportionality assumption with respect to personality traits. Additional goodness-of-fit checks using Cox-Snell residuals indicate that the Cox model fits the data relatively well as can be seen from the corresponding graph in the Appendix (Fig. A4). In order to compare the results for men and women, statistical analyses were run separately for both genders. Analyses with respect to second childbirths were stratified by age at 
first childbirth, rounded down to full years without decimals. The same models were applied regarding the analyses based on personality clusters, only the single personality traits were replaced by the respective cluster variable (3-, 4, or 5-clustersolution).

To examine in additional analyses whether personality is correlated with the number of children at age 40, 45, as well as 50 and later, Poisson regression models were run. I used the identical information on personality as described above. Since this setting focuses on completed fertility, no time-varying variables were required. Thus, observations come from year 2005 at earliest (this is the first wave with personality information) and individuals were only included in the analyses if they were 40 years (45 and 50, respectively) or older by the time of latest survey collection. The Poisson regression models were conducted for the total sample as well as separated by gender and are based on the following equation:

$$
\log \left(y \mid X_{1}, \ldots, X_{p}\right)=\beta_{0}+\beta_{1} \text { Agree }_{i}+\beta_{2} \text { Conscient }_{i}+\beta_{3} \text { Extra }_{i}+
$$

$\beta_{4}$ Neuro $_{i}+\beta_{5}$ Open $_{i}+\beta_{6}$ Gender $_{i}+\beta_{7}$ AgeBaseline $_{i}+$

$\beta_{8}$ YearsEdu $_{i}+\beta_{9}$ EnrolStat $_{i}+\beta_{10}$ CivilStat $_{i}+\beta_{11}$ log Income $_{i}+$ $\beta_{12}$ EduMom $_{i}+\beta_{13}$ EduDad $_{i}+\beta_{14}$ Region $_{i}+\varepsilon_{i}$

The outcome y (here: number of children by age 40 and higher) depends on a set of independent variables $X_{1}, \ldots, X_{p}$. Apart from the outcome, all of the variables and indications are equivalent to the ones used above in equation (1), with the difference that they do not vary over time. 


\section{Results}

\section{Descriptive Results}

The first sample contains individuals who were childless when their personality information was first collected $(2005,2009$, or 2013). These participants either rem ained childless over time, or they gave birth to a first child between 2005 and 2017. Inform ation is available for 5,758 participants and 28,100 observations in total. During the considered time period, 1,065 first childbirths were observed. Table 1 shows the mean values (before standardization of personality traits) and the frequencies of all included characteristics for the total sample, as well as stratified by gender. In general, the mean values of the personality traits are relatively high. In Sample 1, they range from 3.75 (neuroticism) to 5.61 (conscientiousness) on scales from one to seven. Women have higher mean values for all personality traits. The significance of these differences was tested by z-tests, which showed that women and men differ significantly for all five factors. The largestdifferences can be observed for neuroticism (females: 4.08 vs. males: 3.48 ). The most similar mean values can be found for conscientiousness (5.69 vs. 5.54$)$.

[Table 1 about here]

Sam ple 2 refers to all participants with one child and their personality information. The sam ple consists of 2,740 individuals and 11,508 observations. 716 second childbirths were recorded. Compared to the participants in Sample 1, the participants in Sample 2 had slightly higher personality scores (except on openness). In particular, increasing conscientiousness can be observed (Sample 1: 5.61 vs. Sample 2: 5.89). Other 
differences between the two samples can be detected for education and civil status: $36.28 \%$ of the participants in Sample 1, but only $5.22 \%$ of the participants in Sample 2, were enrolled in an education program. Furthermore, the civil status shifted from mainly living alone (62.49\%) in Sample 1 to being married in Sample $2(67.92 \%)$. Further details referring to Sample 2 can be seen in Table 2.

[Table 2 about here]

\section{Survival Models}

In the following, results from CoxPH Survival Models are shown for each trait from the FFM separately. Each graph displays point estimates of hazard ratios $(\mathrm{HR})$ and the corresponding $95 \%$-confidence intervals. Ratios above one indicate a higher likelihood and an acceleration of childbearing, with an increasing score on the respective standardized personality scale. Point estimates below one suggest lower chances of childbearing and postponem ent in childbearing with higher standardized scores. Each graph contains information about the total sam ple, fem ales and males after controlling for all covariates listed earlier. Results are shown for the first and the second childbirth. The $y$-scale is logarithmic for visualization reasons, and its range can vary according to trait-specific results. Estimated coefficients of all considered covariates for the total sam ple and for women and men are listed in Tables A1 and A2 in the appendix. 


\section{Agreeableness}

Figure 1 shows the point-estim ated HR of the association between agreeableness and childbearing for the total sample, as well as for women and men. Among the total sample, agreeableness tends to accelerate childbearing. The HR is $1.07(p<0.1)$ for first childbirths and 1.05 for second childbirths although the latter estimate is not statistically significant. The findings are mainly based on the results am ong males, for whom an estimate of $1.09(p<0.1)$ is calculated for the first childbirth. For women, no statistically significant associations between agreeableness and the first or second childbirth can be found (HR: 1.04 and 0.97$)$.

[Fig. 1 about here]

\section{Conscientiousness}

Results according to conscientiousness are shown in Fig. 2. A negative correlation between conscientiousness and the first childbirth can be detected for males only indicating that men with high scores on this trait tend to postpone the birth of their first child (HR: 0.91, $\mathrm{p}<0.1)$. However, the standard errors are relatively large. For the second childbirth, conscientiousness is negatively linked with fertility among women (HR: $0.87 ; p<0.05)$ so that females with high scores on conscientiousness tend to postpone their second childbirth.

[Fig. 2 about here] 


\section{Extraversion}

Figure 3 illustrates the findings with respect to extraversion and fertility. It shows a positive, albeit statistically non-significant estimate (HR: 1.05) regarding the first childbirth among the entire sample. With respect to the second childbirth, however, a negative link can be found among the total sample (HR: $0.90, p<0.01)$. Therefore, it appears that higher extraversion scores lead to postponements of second childbirth, which contradicts my expectations. These correlations are mainly based on the findings among males, for whom a strong positive association between extraversion and the first childbirth (HR:1.14, $\mathrm{p}<0.01)$, but a negative link between extraversion and the second childbirth, is found (HR: $0.85, p<0.01)$. Contrary to my expectations, no correlations between extraversion and childbearing are observed among women.

[Fig. 3 about here]

\section{Neuroticism}

The correlations between neuroticism and childbearing in my study are shown in Fig.

4. The findings suggest that neuroticism does not play a great role regarding childbearing. This factor is not linked with first childbirth in any (sub-)sam ple. However, a negative association with second childbirths among women can be detected (HR: $0.90 ; p<0.1)$.

[Fig. 4 about here] 


\section{Openness to new experiences}

Figure 5 shows that openness is not correlated with the first childbirth. Additional analyses have shown that a possible negative association (HR:0.90, $p<0.01)$ vanishes when civil status is included in the model. If a negative link exists at all, it is for males (HR: 0.94). However, the confidence intervals are relatively large and the estimate is not statistically significant. For the second childbirth, a positive but not statistically significant relationshipcan be observed across all sam ples, and in particular for women (HR: 1.07).

[Fig. 5 about here]

\section{Mediators}

Additional checks were perform ed to examine the effects of mediators (family status, education, income). The models without these variables did not differ greatly in their personality trait coefficients, as can be seen in the Appendix (Fig. A5-A8). Most often, including potential mediators in the models did not affect the personality coefficients very much. The only exception from this pattern is openness. Models excluding mediators revealed a statistically significant and negative association between this factor and first childbirth among the total sample (HR: 0.90; $p<0.01)$, females (HR: $0.91 ; \mathrm{p}<0.05)$ and males (HR:0.86; $\mathrm{p}<0.01)$. After including mediators, and in particular civil status, this correlation became statistically non-significant. The corresponding hazard ratios can be seen in Fig. 6 below. 
[Fig. 6 about here]

\section{Personality clusters}

Additionally, I ran analyses using personality clusters based on K-m eans clustering procedure. However, I did not find statistically significant associations between any personality type and fertility, regardless of whether the approach was based on three, four, or five personality types. This was found to be the case among the entire sam ple, men and women for both the first and the second childbirth. Results regarding personality clusters are shown in Appendix (Tables A3 + A4).

\section{Number of children}

Furthermore, Poisson regression models were conducted to analyze the correlation between personality factors and the number of children. This perspective com plements the present study, which focuses on the age at childbirth and the probability of having a first or a second child only. However, the number of children cannot be considered under a prospective design because the data follow-up is still not sufficiently extensive. Therefore, the number of children at the end of each individual's fertility history - i.e., above 40,45 , and 50 years of age - is used (Table A5 in appendix). The results indicate that agreeableness and extraversion are positively related to the number of children, whereas conscientiousness and openness are linked with having fewer children. The findings with respect to women are of particular interest, as statistically significant fertility associations can be found with agreeableness (positive), conscientiousness (negative), and extraversion (positive). This implies that personality is correlated with fertility among women, a finding that did not emerge from the 
prospective analyses on entry into parenthood of the present study. Why personality would be linked with the number of children a woman has, but not with the timing of her first childbirth, is a question that remains open. This could be explained by the point in time when the information on personality was collected (before childbirth vs. at the end of fertility history), since having and raising children can affect personality, which in turn rather affects the timing of second childbirth and the total number of children.

\section{Discussion}

This study examined the association between personality traits from the FFM and childbearing in Germany over a 12-year follow-up period. Among the total sample, findings from analyses based on German data from the SOEP indicated that agreeableness tended to accelerate the first childbirth, whereas conscientiousness, neuroticism, and openness did not affect childbearing after controlling for sociodemographic covariates. Extraversion was shown to have the most striking correlations with fertility. This trait tended to be positively connected with the first, but had negative associations with the second childbirth.

These results were mainly driven by males, although conscientiousness and neuroticism were negatively associated with second childbirths am ong women. These gender-specific findings are partly in line with previous research. The strong and positive associations between extraversion and first childbirth among males but not among females might be attributed to the positive correlations of this trait with the number of sexual partners am ong men, but not among women (Allen \& Desille 2017). Furthermore, agreeableness tended to accelerate the first childbirth within the total sam ple, even after controlling for sociodem ographic covariates. This finding is mainly 
driven by males. Additionally, conscientiousness was negatively linked with first childbirth (males only), and with second childbirths (only for females). Again, this corresponded only partly with the findings of previous studies that reported correlations between agreeableness (positive) and fertility, as well as between conscientiousness (negative) and fertility (Allen 2019). Neuroticism was negatively linked with second childbirths among women. This association is in line with findings from previous research that shows a negative correlation between neuroticism and fertility among females (Jokela 2012). Therefore, these women may tend to postpone the second childbirth, or even never experience this event, in order to increase their own em otional stability first.

Since personality is not linked with first childbirths among females, the findings of the present study indicate that wom en might choose to enter motherhood independent of their personality traits, whereas men seem to enter fatherhood due to specific personality dimensions. The different results between the first and the second childbirths might be explained by the differences between these transitions. It may be the case that the transition from being childless to being a parent is characterized by larger adjustments in daily life than the transition to having a second child. For instance, when a first child is born, the social life of extraverted individuals could be restricted by their child care responsibilities, which may prevent them from meeting with their friends. Therefore, these people could be trying to get their previous social life back by postponing the second childbirth, if they experience it at all. Moreover, extraversion is also positively associated with infidelity (Orzeck \& Lung 2005), which might result in lower levels of partnership stability and, consequently, lower chances to get a second child. 
Over the study period of the present analyses (2005-2017), the total fertility rate in Germany increased from 1.36 to 1.57 (Human Fertility Database 2020). In general, fertility has increased more among older people than it has decreased among younger people (Human Fertility Database 2020). Another possible explanation is that the number of immigrants, who usually have higher fertility levels than the indigenous population, increased over this period (Schmid \& Kohls 2010). However, changes in personality traits across generations may have contributed to these trends as well. Indeed, Jean M. Twenge, in collaboration with others, observed for the U.S. context that several personality facets changed over time across generations of college students and children, e.g. anxiety/neuroticism (Twenge 2000), self-esteem (Twenge \& Campbell 2001), and narcissism (Twenge et al. 2008). In particular, Twenge found that extraversion levels increased over time across generations of students in the U.S. (Twenge 2001). These changes in personality factors were identified among U.S. college students during the last decades of the 20th century only. However, it is reasonable to assume that similar developments have taken place in other societies as well, such as in Germany, although the empirical evidence that this is the case is missing. Personality changes on the population level are shaped by the societal context, as Twenge suggested in her studies. However, these changes can also affect fertility levels in the long run. If, for instance, people are encouraged to be more sociable and talkative - i.e., more extraverted - this could improve their chances of meeting a potential partner for a romantic relationship, which could increase their fertility.

The present study has several strengths and limitations. On the one hand, this study did not address certain issues, such as personality associations among higher birth orders. The sample sizes and number of events for third or higher order childbirths were too small to allow us to draw significant conclusions about the link between 
personality and fertility for these births. However, previous research has suggested that for higher parities, the associations between childbirth and personality traits might be different (Jokela \& Keltikangas-Järvinen 2009). To examine these questions, larger datasets are required. Another limitation of this study is that the respondents' personality traits were considered separately, even though each individual had all of these dimensions. Additional analyses did not reveal associations between personality clusters and the first or the second childbirth, but correlations with other fertility outcomes, such as number of children, remain to be explored. Therefore, personality types that include these five factors might be the focus of future research. Moreover, there were some conceptual problems that could not be resolved within the present analyses. For instance, this study did not distinguish between planned and unplanned pregnancies, even though personality traits can affect planned and unplanned pregnancies differently, as Berg and colleagues (2013) have shown. Furthermore, while the FFM might represent the main personality traits very well, there are some other personality factors that might complement those included in the FFM, such as honesty-humility (Ashton \& Lee 2005) or the willingness to take risks (Caliendo et al. 2014). The latter trait was controlled for in additional analyses, but no associations between this facet and fertility could be found, and the personality trait coefficients did not change very much either.

This study also has certain strengths. First, several previous analyses focused on the first childbirth only. The present study, by contrast, has shown that there are differences in the personality coefficients between the first and the second childbirth. A couple of previous studies distinguished between the first, the second, and the third childbirth. However, these analyses did not consider factors from the FFM, which is the most widely accepted personality inventory currently available. Moreover, many of these studies were based on cross-sectional data, whereas the present study was able 
to capture changes over time, as well as the prospective association between personality traits and childbearing using longitudinal data. This represents an im portant contribution, since the previous research on this relationship was either focused on repeated measurements - i.e., the information on personality was collected at one point in time and fertility was measured at some later point in time - or was based on pers onality measures taken at the end of people's fertility histories, and could therefore only draw retrospective conclusions. These conclusions might have referred to the effects of fertility on personality, but not the other way around. By contrast, this study used longitudinal survey data in which the personality inform ation was collected before (possible) childbearing. The present study illustrated that using the prospective approach can generate unexpected results, such as no associations among females. Furthermore, connections between personality and fertility have not previously been explored for the German context, except in one study by Hutteman and colleagues (2013), who used a smaller dataset (PAIRFAM) and other personality measures (selfesteem, shyness, and aggressiveness).

In general, the findings of the present study contribute to the existing literature by focusing on the prospective association between personality factors from the FFM and fertility outcomes within the German context. Comparing results of my analyses to studies from previous research, certain inconsistencies in the correlation between personality and fertility can be revealed. Findings tend to differ between countries and study designs. Thus, more research is required to disentangle the prospective impact of personality on childbearing. Longitudinal designs that consider personality changes over time will provide deeper insight into the causal effects of personality on fertility. In addition, to obtain a better understanding of fertility motivations, more attention should be paid to a wider range of personality traits and personality types. Furtherm ore, having 
access to population-based data would allow researchers to explore the link between personality and higher birth orders.

\section{Acknowlegements}

I would like to thank all reviewers and colleagues for helpful suggestions in order to improve the quality of this paper. Special thanks go to my supervisors Mikko Myrskylä, and in particular Kieron Barclay for supporting me along the path to publication. I am also grateful for any kind of support provided by the Max Planck Institute for Demographic Research and Stockholm University. 


\section{References}

Allen, Mark S. 2019. "The Role of Personality in Sexual a nd Reproductive Health." Current Directions in Psychological Science 28 (6): 581-86. https://doi.org/10.1177/0963721419862293.

Allen, Mark S., and Annelil E. Desille. 2017. "Personality a nd Sexuality in Older Adults." Psychology and Health 32 (7): 843-59.

Alvergne, A., M. Jokela, and V. Lummaa. 2010. "Pers onality and Reproductive Success in a High-Fertility Human Population." Proceedings of the National Academy of Sciences 107 (26): 11745-50. https://doi.org/10.1073/pnas.1001752107.

Ardelt, Monika. 2000. "Still Stable after All These Years? Personality Stability Theory Revisited." Social Psychology Quarterly 63 (4): 392-405. https://doi.org/10.2307/2695848.

As endorpf, Jens B., a nd Susanne Wilpers. 1998. "Pers onality Effects on Social Relationships." Journal of Personality and Social Psychology 74 (6): 1531-44. https://doi.org/10.1037/0022-3514.74.6.1531.

As hton, Michael C., and Kibeom Lee. 2005. "Honesty-Humility, the Big Five, and the FiveFactor Model." Journal of Personality 73 (5): 1321-54. https://doi.org/10.1111/j.1467-6494.2005.00351.x.

Avis on, Margaret, and Adrian Furnham. 2015. "Personality and Voluntary Childlessness." Journal of Population Research 32 (1): 45-67. https://doi.org/10.1007/s12546-0149140-6.

Baizán, Pau, Arnstein Aassve, and Francesco C. Billari. 2003. "The Interrelations Between Coha bitation, Ma rriage and First Birth in Germany and Sweden." Population and Environment 25 (6): 531-61. https://doi.org/10.1023/B:POEN.0000039064.65655.3b.

Balbo, Nicoletta, Francesco C. Billari, and Melinda Mills. 2013. "Fertility in Advanced Societies: A Review of Research: La Fécondité Dans Les Sociétés Avancées: Un Examen Des Recherches." European Journal of Population / Revue Européenne de Démographie 29 (1): 1-38. https://doi.org/10.1007/s10680-012-9277-y.

Bar, Micha el, Moshe Hazan, Oksana Leukhina, David Weiss, and Hosny Zoabi. 2018. "Why Did Rich Families Increase Their Fertility? Inequality a nd Marketization of Child Care." Journal of Economic Growth 23 (4): 427-63. https ://doi.org/10.1007/s10887-0189160-8.

Barbaranelli, Claudio. 2002. "Evaluating Cluster Analysis Solutions: An Application to the Italian NEO Personality Inventory." European Journal of Personality 16 (S1): S43-55. https://doi.org/10.1002/per.449.

Berg, Venla, Anna Rotkirch, Heini Väisänen, and Markus Jokela. 2013. "Personality Is Differentially Associated with Planned and Non-Planned Pregnancies." Journal of Research in Personality 47 (4): 296-305. https://doi.org/10.1016/j.jrp.2013.01.010.

Bernardi, Laura, and Andreas Klaerner. 2014. "Social Networks and Fertility." Demographic Research 30 (March): 641-70. https://doi.org/10.4054/DemRes.2014.30.22.

Bleidorn, Wiebke, Christopher J. Hopwood, and Richard E. Lucas. 2018. "Life Events and Pers onality Tra it Change: Life Events and Trait Change." Journal of Personality 86 (1): 83-96. https://doi.org/10.1111/jopy.12286.

Blossfeld, Hans-Peters, and Johannes Huinink. 1991. "Human Ca pital Investments or Norms of Role Transition? How Women's Schooling and Career Affect the Process of Family Formation." American Journal of Sociology 97 (1): 143-68. 
Borghuis, Jeroen, Jaap J A Denissen, Daniel Ob erski, Klaas Sijtsma, Wim H J Meeus, Susan Branje, Hans M Koot, and Wiebke Bleidorn. 2017. "Big Five Personality Sta bility, Change, and Codevelopment Across Adolescence and Early Adulthood." Journal of Personality and Social Psychology 113 (4): 641-57.

Boudreau, John W., Wendy R. Boswell, and Timothy A. Judge. 2001. "Effects of Personality on Executive Career Success in the United States and Europe." Journal of Vocational Behavior 58 (1): 53-81. https://doi.org/10.1006/jvbe.2000.1755.

Boyce, Christopher J., Alex M. Wood, and Eamonn Ferguson. 2016. "For Better or for Wors e: The Moderating Effects of Personality on the Ma rriage-Life Satisfaction Link." Personality and Individual Differences 97 (July): 61-66. https://doi.org/10.1016/j.paid.2016.03.005.

Bozionelos, Nikos. 2004. "The Relationship between Disposition and Ca reer Success: A British Study." Journal of Occupational and Organizational Psychology 77 (3): 403-20. https://doi.org/10.1348/0963179041752682.

Brien, Michael J., Lee A. Lillard, and Linda J. Waite. 1999. "Interrelated Family-Building Behaviors: Cohabitation, Ma rriage, and Nonmarital Conception." Demography 36 (4): 535-51. https://doi.org/10.2307/2648089.

Britzke, Janina, and Jürgen Schupp, eds. 2018. "SOEP Wave Report 2017," SOEP Wave Report, , no. 2017. http://hdl.handle.net/10419/191296.

Buss, David M, and Michael Barnes. 1986. "Preferences in Human Mate Selection." Journal of Personality and Social Psychology 50 (3): 559-70.

Caliendo, Marco, Frank Fossen, and Alexander S. Kritikos. 2014. "Perso nality Cha racteristics and the Decisions to Become and Stay Self-Employed." Small Business Economics 42 (4): 787-814. https://doi.org/10.1007/s11187-013-9514-8.

Chen, I-Chun. 2016. "Pa rental Education and Fertility: An Empirical Investigation Based on Evidence from Taiwan." Journal of Family and Economic Issues 37 (2): 272-84. https://doi.org/10.1007/s10834-015-9448-1.

Córdoba, Juan Carlos, and Marla Ripoll. 2016. "Intergenera tional Transfers and the FertilityIncome Relationship." The Economic Journal 126 (593): 949-77. https://doi.org/10.1111/ecoj.12197.

Cos ta Jr., Pa ul T., Robert R. McCrae, and David A. Dye. 1991. "Fa cet Scales for Agreeableness and Conscientiousness: A Revision of the NEO Personality Inventory." Personality and Individual Differences 12 (9): 887-98.

Cragar, Dona E., David T.R. Berry, Frederick A. Schmitt, and Toufic A. Fakhoury. 2005. "Clus ter Analysis of Normal Personality Traits in Patients with Psychogenic Nonepileptic Seizures." Epilepsy \& Behavior 6 (4): 593-600. https://doi.org/10.1016/j.yebeh.2005.03.007.

Dahlberg, Johan, and Martin Kolk. 2018. "Explaining Swedish Sibling Similarity in Fertility: Parental Fertility Behavior vs. Social Background." Demographic Research 39 (October): 883-96. https://doi.org/10.4054/DemRes.2018.39.32.

Destatis. 2019. "Press release No. 332 of 3 September 2019" Statistisches Bundesamt (Destatis), 2019. https://www.destatis.de/EN/Press/2019/09/PE19_332_122.html;jsessionid=87E16A2 C332CCFBE407D5A56D098E966.internet742.

Destatis. 2020. "Source: Gebiet, Bevölkerung, Arbeitsmarkt, Wahlen - Bevölkerung - Statistik derGeburten - Zusammengefasste Geburtenziffern (je Frau): Bundesländer, Ja hre, Al te rsgruppen" Statistisches Bundesamt (Destatis), 2020. 
https://www-

genesis.destatis.de/genesis/online?operation=ergebnistabelleKarte \&option=karte \&k artenTyp=0\&levelindex=2\&levelid=1584107138409\&downloadname=\#abreadcrumb.

Donnellan, M. Brent, and Richard E. Lucas. 2008. "Age Differences in the Big Five across the Life Span: Evidence from Two National Samples." Psychology and Aging 23 (3): 55866. https://doi.org/10.1037/a0012897.

Donnellan, M.Brent, Rand D. Conger, and Chalandra M. Bryant. 2004. "The Big Five and Enduring Ma rriages." Journal of Research in Personality 38 (5): 481-504. https://doi.org/10.1016/j.jrp.2004.01.001.

Eaves, L. J., N. G. Martin, A. C. Heath, J. K. Hewitt, and M. C. Neale. 1990. "Personality and Reproductive Fitness." Behavior Genetics 20 (5): 563-68. https://doi.org/10.1007/BF01065872.

Elder Jr., Glen H., and Deborah J. Ma cInnis. 1983. "Achievement Imagery in Women's Lives From Adolescence to Adulthood." Journal of Personality and Social Psychology 45 (2): 394-404.

Fisher, Terri D., and James K. McNulty. 2008. "Neuroticism and Ma rital Satisfaction: The Mediating Role Played by the Sexual Relationship." Journal of Family Psychology 22 (1): 112-22. https://doi.org/10.1037/0893-3200.22.1.112.

Friedman, Debra, Michael Hechter, and Satoshi Kanazawa. 1994. "A The ory of the Value of Children." Demography 31 (3): 375-401.

Gelissen, John, and Paul M. de Graaf. 2006. "Personality, Social Background, and Occupa tional Career Success." Social Science Research 35 (3): 702-26. https://doi.org/10.1016/j.ssresearch.2005.06.005.

Germeijs, Veerle, and Ka rine Verschueren. 2011. "Indecisiveness and Big Five Personality Factors: Relationship and Specificity." Personality and Individual Differences 50 (7): 1023-28. https://doi.org/10.1016/j.paid.2011.01.017.

Gershuny, Beth S, and Kenneth J Sher. 1998. "The Relation Between Personality and Anxiety: Findings From a 3-Year Pros pective Study." Journal of Abnormal Psychology 107 (2): 252-62.

Goebel, Jan, Markus M. Grabka, Stefan Liebig, Martin Kroh, David Richter, Carsten Schröder, and Jürgen Schupp. 2019. "The German Socio-Economic Panel (SOEP)." Jahrbücher Für Nationalökonomie Und Statistik 239 (2): 345-60. https://doi.org/10.1515/jbnst2018-0022.

Goldberg, Lewis R. 1993. "The Structure of Phenotypic Personality Tra its." American Psychologist, 9.

Gustafsson, Siv. 2001. "Optimal Age at Motherhood. Theoretical and Empirical Considerations on Postponement of Maternity in Europe." Journal of Population Economics 14: 225-47.

Holland, Ashley S., and Glenn I. Roisman. 2008. "Big Five Personality Traits and Relationship Quality: Self-Reported, Observational, and Physiological Evidence." Journal of Social and Personal Relationships 25 (5): 811-29. https://doi.org/10.1177/0265407508096697.

Holton, Sara, Jane Fisher, and Heather Rowe. 2009. "Attitudes Toward Women and Motherhood: Their Role in Australian Women's Childbearing Behaviour." Sex Roles 61 (9-10): 677-87. https://doi.org/10.1007/s11199-009-9659-8.

Hopcroft, Rosemary L. 2006. "Sex, Sta tus, and Reproductive Success in the Contemporary United States." Evolution and Human Behavior 27 (2): 104-20. https://doi.org/10.1016/j.evolhumbehav.2005.07.004. 
Hopwood, Christopher J, and Wiebke Bleidorn. 2018. "Sta bility and Change in Personality and Personality Disorders." Current Opinion in Psychology 21 (June): 6-10. https://doi.org/10.1016/j.copsyc.2017.08.034.

Hutteman, Roos, Wiebke Bleidorn, Lars Penke, and Ja ap J. A. Denissen. 2013. "It Takes Two: A Longitudinal Dyadic Study on Predictors of Fertility Outcomes: Dyadic Predictors of Fertility Outcomes." Journal of Personality 81 (5): 487-98. https://doi.org/10.1111/jopy.12006.

Johns, Sarah E., Thomas E. Dickins, and Helen T. Clegg. 2011. "Teenage Pregnancy and Motherhood: How Might Evolutionary Theory Inform Policy?" Journal of Evolutionary Psychology 9 (1): 3-19. https://doi.org/10.1556/JEP.9.2011.37.1.

Jokela, Markus. 2012. "Birth-Cohort Effects in the Association Between Personality and Fertility." Psychological Science 23 (8): 835-41. https://doi.org/10.1177/0956797612439067.

Jokela, Markus, Alexandra Alvergne, Thomas V. Pollet, and Virpi Lummaa. 2011. "Reproductive Behavior and Personality Traits of the Five Factor Model." European Journal of Personality 25 (6): 487-500. https://doi.org/10.1002/per.822.

Jokela, Markus, and Liisa Keltikangas-Järvinen. 2009. "Adolescent Leadership and Adulthood Fertility: Revisiting the 'Central Theoretical Problem of Human Sociobiology.'” Journal of Personality 77 (1): 213-30. https://doi.org/10.1111/j.1467-6494.2008.00543.x.

Jokela, Markus, Mika Kivimäki, Marko Elovainio, and Liisa Keltikangas-Järvinen. 2009. "Pers onality and Having Children: A Two-Way Relationship." Journal of Personality and Social Psychology 96 (1): 218-30. https://doi.org/10.1037/a0014058.

Judge, Timothy A., and Remus Ilies. 2002. "Relationship of Personality to Performance Motivation: A Meta-Analytic Review." Journal of Applied Psychology 87 (4): 797-807. https://doi.org/10.1037/0021-9010.87.4.797.

Karney, Benjamin R, and Thomas N Bradbury. 1997. "Neuroticism, Marital Interaction, and the Tra jectory of Ma rital Satisfaction." Journal of Personality and Social Psychology 72 (5): 1075-92.

Ka ufman, Gayle. 2000. "Do Gender Role Attitudes Matter? Family Formation and Dissolution Among Tra ditional and Egalitarian Men and Women." Journal of Family Issues 21 (1): 128-44.

Ka ufman, Gayle, and Eva Bernhardt. 2012. "His and Her Job: What Matters Most for Fertility Plans and Actual Childbearing?" Family Relations 61 (4): 686-97. https://doi.org/10.1111/j.1741-3729.2012.00720.x.

Koo, Terry K., and Ma e Y. Li. 2016. "A Guideline of Selecting and Reporting Intra class Correlation Coefficients for Reliability Research." Journal of Chiropractic Medicine 15 (2): 155-63. https://doi.org/10.1016/j.jcm.2016.02.012.

Kramarz, Francis, Oskar Nordström Skans, and Olof Rosenqvist. 2019. "Skills, education and fertility a nd the confounding impact of fa mily background", Working Paper, No. 2019: 10, Institute for Eva luation of Labour Market and Education Policy (IFAU), Uppsala.

Li, Norman P., J. Micha el Bailey, Douglas T. Kenrick, and Joan A. W. Linsenmeier. 2002. "The Necessities and Luxuries of Mate Preferences: Testing the Tra deoffs." Journal of Personality and Social Psychology 82 (6): 947-55. https://doi.org/10.1037/00223514.82.6.947.

Lillard, Lee A., and Linda J. Waite. 1993. "A Joint Model of Marital Childbearing and Ma rital Disruption." Demography 30 (4): 653-81. https ://doi.org/10.2307/2061812. 
Lucas, Richard E., and M. Brent Donnellan. 2011. "Pers onality Development across the Life Span: Longitudinal Analyses with a National Sample from Germany." Journal of Personality and Social Psychology 101 (4): 847-61.

https://doi.org/10.1037/a0024298.

Lucie Schmidt. 2008. "Risk Preferences and the Timing of Ma rriage a nd Child bearing." Demography 45 (2): 439-60. https ://doi.org/10.1353/dem.0.0005.

Lundberg, Shelly. 2012. "Pers onality a nd Marital Surplus." IZA Journal of Labor Economics 1 (1): 1-21.

Malouff, John M., Einar B. Thorsteinsson, Nicola S. Schutte, Navjot Bhullar, a nd Sally E. Rooke. 2010. "The Five-Factor Model of Personality a nd Relationship Satisfaction of Intimate Partners: A Meta-Analysis." Journal of Research in Personality 44 (1): 12427. https://doi.org/10.1016/j.jrp.2009.09.004.

McAllister, Lisa S., Gillian V. Pepper, Sandra Virgo, and David A. Coall. 2016. "The Evolved Psychological Mechanisms of Fertility Motivation: Hunting for Causation in a Sea of Correlation." Philosophical Transactions of the Royal Society B: Biological Sciences 371 (1692): 20150151. https://doi.org/10.1098/rstb.2015.0151.

McCrae, Robert R. 1996. "Social Consequences of Experiential Openness." Psychological Bulletin 120 (3): 323-37.

McCrae, Robert R, and Paul T Costa. 1987. "Validation of the Five-Factor Model of Pers onality Across Instruments and Observers." Journal of Personality and Social Psychology 52 (1): 81-90.

McNulty, James K. 2008. "Neuroticism and Interpersonal Negativity: The Independent Contributions of Perceptions and Behaviors." Personality and Social Psychology Bulletin 34 (11): 1439-50. https://doi.org/10.1177/0146167208322558.

Meyer, Jennifer, Johanna Fleckenstein, Jan Retelsdorf, and Olaf Köller. 2019. "The Relationship of Personality Traits and Different Measures of Domain-Specific Achievement in Upper Secondary Education." Learning and Individual Differences 69 (January): 45-59. https ://doi.org/10.1016/j.lindif.2018.11.005.

Miller, Joshua D, Donald Lynam, Rick S Zimmerman, T.K Logan, Carl Leukefeld, and Richard Clayton. 2004. "The Utility of the Five Factor Model in Understanding Risky Sexual Behavior." Personality and Individual Differences 36 (7): 1611-26. https://doi.org/10.1016/j.paid.2003.06.009.

Miller, Warren B. 1992. "Pers onality Traits and Developmental Experiences as Antecedents of Childbearing Motivation." Demography 29 (2): 265-85. https://doi.org/10.2307/2061731.

Monsta d, Ka rin, Ca rol Propper, and Kjell G. Salvanes. 2008. "Education and Fertility: Evidence from a Natural Experiment*." Scandinavian Journal of Economics 110 (4): 827-52. https://doi.org/10.1111/j.1467-9442.2008.00563.x.

Nettle, Daniel. 2005. "An Evolutionary Approach to the Extraversion Continuum." Evolution and Human Behavior 26 (4): 363-73. https://doi.org/10.1016/j.evolhumbehav.2004.12.004.

- - . 2006. "The Evolution of Personality Va riation in Humans and Other Animals." American Psychologist 61 (6): 622-31. https ://doi.org/10.1037/0003-066X.61.6.622.

Neyer, Franz J., and Jens B. As endorpf. 2001. "Personality-Relationship Transaction in Young Adulthood." Journal of Personality and Social Psychology 81 (6): 1190-1204. https://doi.org/10.1037//0022-3514.81.6.1190. 
Orth, Ulrich. 2013. "How Large Are Actor a nd Partner Effects of Personality on Relationship Satisfaction? The Importance of Controlling for Shared Method Variance." Personality and Social Psychology Bulletin 39 (10): 1359-72.

Orzeck, Tricia, and Esther Lung. 2005. "Big-Five Personality Differences of Cheaters and NonChea ters." Current Psychology 24 (4): 274-86. https://doi.org/10.1007/s12144-0051028-3.

Perkins, Patrick Scott, Jennifer D. Slane, and Kelly L. Klump. 2013. "Personality Clusters and Family Relationships in Women with Disordered Eating Symptoms." Eating Behaviors 14 (3): 299-308. https://doi.org/10.1016/j.eatbeh.2013.05.007.

Pinquart, Martin, Martin Stotzka, and Rainer K. Silbereisen. 2008. "Pers onality and Ambivalence in Decisions a bout Becoming Pa rents." Social Behavior and Personality: An International Journal 36 (1): 87-96.

Puur, Alla n, Livia Sz. Oláh, Ma riam Irene Tazi-Preve, and Jürgen Dorbritz. 2008. “Men's Childbearing Desires and Views of the Male Role in Europe at the Dawn of the 21st Century." Demographic Research 19 (November): 1883-1912. https://doi.org/10.4054/DemRes.2008.19.56.

Retherford, Robert D., and William H. Sewell. 1989. "How Intelligence Affects Fertility." Intelligence 13 (2): 169-85. https://doi.org/10.1016/0160-2896(89)90015-9.

Roberts, Brent W., and Timothy Bogg. 2004. "A Longitudinal Study of the Relationships Between Conscientiousness and the Social- Environmental Factors and SubstanceUse Behaviors That Influence Health." Journal of Personality 72 (2): 325-54. https://doi.org/10.1111/j.0022-3506.2004.00264.x.

Sava, Florin A, and Radu I Popa. 2011. "Personality Types Based on the Big Five Model. A Cluster Analysis over the Romanian Population." Cognition, Brain, Behavior 15 (3): 359-84.

Schimmack, Ulrich, Jürgen Schupp, a nd Gert G. Wagner. 2008. "The Influence of Environment and Personality on the Affective and Cognitive Component of Subjective Well-Being." Social Indicators Research 89 (1): 41-60. https://doi.org/10.1007/s11205-007-9230-3.

Schmid, Susanne, and Martin Kohls. 2010. "Fertility of Female Immigrants in Germany." In Demographic Aspects of Migration, edited by Thomas Salzmann, Barry Edmonston, and James Raymer, 179-207. Wies baden: VS Verlag für Sozialwissenschaften. https://doi.org/10.1007/978-3-531-92563-9_7.

Schmitt, David P. 2004. "The Big Five Related to Risky Sexual Behaviour across 10 World Regions: Differential Personality Associations of Sexual Promiscuity and Relationship Infidelity." European Journal of Personality 18 (4): 301-19. https://doi.org/10.1002/per.520.

Schmitt, David P., and Todd K. Shackelford. 2008. "Big Five Traits Related to Short-Term Mating: From Personality to Promiscuity a cross 46 Nations." Evolutionary Psychology 6 (2): 246-82. https://doi.org/10.1177/147470490800600204.

Siegers, Rainer, Veronika Belcheva, and Tobias Silbermann. 2019. "SOEP-Core V34 Documentation of Sample Sizes and Panel Attrition in the German Socio-Economic Panel (SOEP) (1984 until 2017)." SOEP Survey Papers 606 Series C.

Sijtsma, Klaas. 2009. "On the Use, the Misuse, and the Very Limited Usefulness of Cronbach's Al pha." Psychometrika 74 (1): 107-20. https://doi.org/10.1007/s11336-008-9101-0.

Skirbekk, Vegard. 2008. "Fertility Trends by Social Status." Demographic Research 18 (March): 145-80. https://doi.org/10.4054/DemRes.2008.18.5. 
Skirbekk, Vegard, and Morten Blekesaune. 2014. "Personality Traits Increasingly Important for Male Fertility: Evidence from Norway: Personality Traits and Male Fertility." European Journal of Personality 28: 521-29. https://doi.org/10.1002/per.1936.

Sobotka, Tomáš, Éva Beaujouan, and Jan Van Bavel. 2018. "Introduction: Education and Fertility in Low-Fertility Settings." Vienna Yearbook of Population Research 1: 1-16. https://doi.org/10.1553/populationyearbook2017s001.

Sodermans, An Katrien, Martine Corijn, Sofie Vanassche, and Koen Matthijs. 2017. "Effects of Pers onality on Postdivorce Partnership Trajectories." Journal of Social and Personal Relationships 34 (7): 1031-52. https://doi.org/10.1177/0265407516665250.

Solomon, Britta ny C., and Joshua J. Jackson. 2014. "Why Do Personality Traits Predict Divorce? Multiple Pa thways through Satisfaction." Journal of Personality and Social Psychology 106 (6): 978-96. https://doi.org/10.1037/a0036190.

Specht, Jule, Boris Egloff, and Stefan C. Schmukle. 2011. "Sta bility and Change of Personality across the Life Course: The Impact of Age and Major Life Events on Mean-Level and Rank-Order Stability of the Big Five." Journal of Personality and Social Psychology 101 (4): 862-82. https://doi.org/10.1037/a0024950.

Spéder, Zsolt, and Balázs Kapitány. 2009. “How Are Time-Dependent Child bearing Intentions Realized? Realization, Postponement, Abandonment, Bringing Forward: Les Intentions de Fécondité Sont-Elles Réalisées Dans Le Délai Prévu ? Réalisation, Report, Abandon, Ava ncement." European Journal of Population / Revue Européenne de Démographie 25 (4): 503-23. https://doi.org/10.1007/s10680-009-9189-7.

Sutin, Angelina R., Paul T. Costa, Richard Miech, and William W. Eaton. 2009. "Pers onality and Career Success: Concurrent and Longitudinal Relations." European Journal of Personality 23 (2): 71-84. https ://doi.org/10.1002/per.704.

Sutin, Angelina R., Martina Luchetti, Yannick Stephan, Richard W. Robins, and Antonio Terracciano. 2017. "Parental Educational Attainment and Adult Offspring Personality: An Intergenerational Life Span Approach to the Origin of Adult Personality Traits." Journal of Personality and Social Psychology 113 (1): 144-66. https://doi.org/10.1037/pspp0000137.

Tavakol, Mohsen, and Reg Dennick. 2011. "Making Sense of Cronbach's Alpha." International Journal of Medical Education 2 (June): 53-55. https://doi.org/10.5116/ijme.4dfb.8dfd.

Tava res, Lara Pa trício. 2016. "Who Delays Childbearing? The Associations Between Time to First Birth, Personality Traits and Education." European Journal of Population 32 (4): 575-97. https://doi.org/10.1007/s10680-016-9393-1.

Thomas, Frederic, Francois Renaud, Eric Benefice, Thierry de Meeus, and Jean-Francois Guegan. 2001. "International Va riability of Ages at Menarche and Menopause: Patterns and Ma in Determinants." Human Biology 73 (2): 271-90. https://doi.org/10.1353/hub.2001.0029.

Twenge, Jean M. 2000. "The Age of Anxiety? Birth Cohort Change in Anxiety and Neuroticism, 1952-1993." Journal of Personality and Social Psychology 79 (6): 100721.

- - - 2001. "Birth Cohort Changes in Extraversion: A Cross-Temporal Meta-Analysis, 19661993." Personality and Individual Differences 30 (5): 735-48.

Twenge, Jean M., and W. Keith Campbell. 2001. "Age and Birth Cohort Differences in SelfEsteem: A Cross-Temporal Meta-Analysis." Personality and Social Psychology Review 5 (4): 321-44. https://doi.org/10.1207/S15327957PSPR0504_3. 
Twenge, Jean M., Sara Konrath, Joshua D. Foster, W. Keith Campbell, and Brad J. Bushman. 2008. "Egos Inflating Over Time: A Cross-Temporal Meta-Analysis of the Narcissistic Pers onality Inventory." Journal of Personality 76 (4): 875-902. https://doi.org/10.1111/j.1467-6494.2008.00507.x.

Uher, Jana. 2017. "Open Peer Commentary and Authors' Response: Comments." European Journal of Personality 31 (5): 529-95. https://doi.org/10.1002/per.2128.

Van Bavel, Jan. 2010. "Choice of Study Discipline and the Postponement of Motherhood in Europe: The Impact of Expected Earnings, Gender Composition, and Family Attitudes." Demography 47 (2): 439-58. https ://doi.org/10.1353/dem.0.0108.

Van Hiel, Alain, and Ivan Mervielde. 2004. "Openness to Experience and Boundaries in the Mind: Relationships with Cultural and Economic Conservative Beliefs." Journal of Personality 72 (4): 659-86. https://doi.org/10.1111/j.0022-3506.2004.00276.x.

Wainwright, Mark A., Margaret J. Wright, Michelle Luciano, Gina M. Geffen, and Nicholas G. Martin. 2008. "Genetic Cova riation Among Facets of Openness to Experience and General Cognitive Ability." Twin Research and Human Genetics 11 (3): 275-86. https://doi.org/10.1375/twin.11.3.275. 


\section{Appendix}

Fig. A1: Personality mean values in 3-cluster-solution

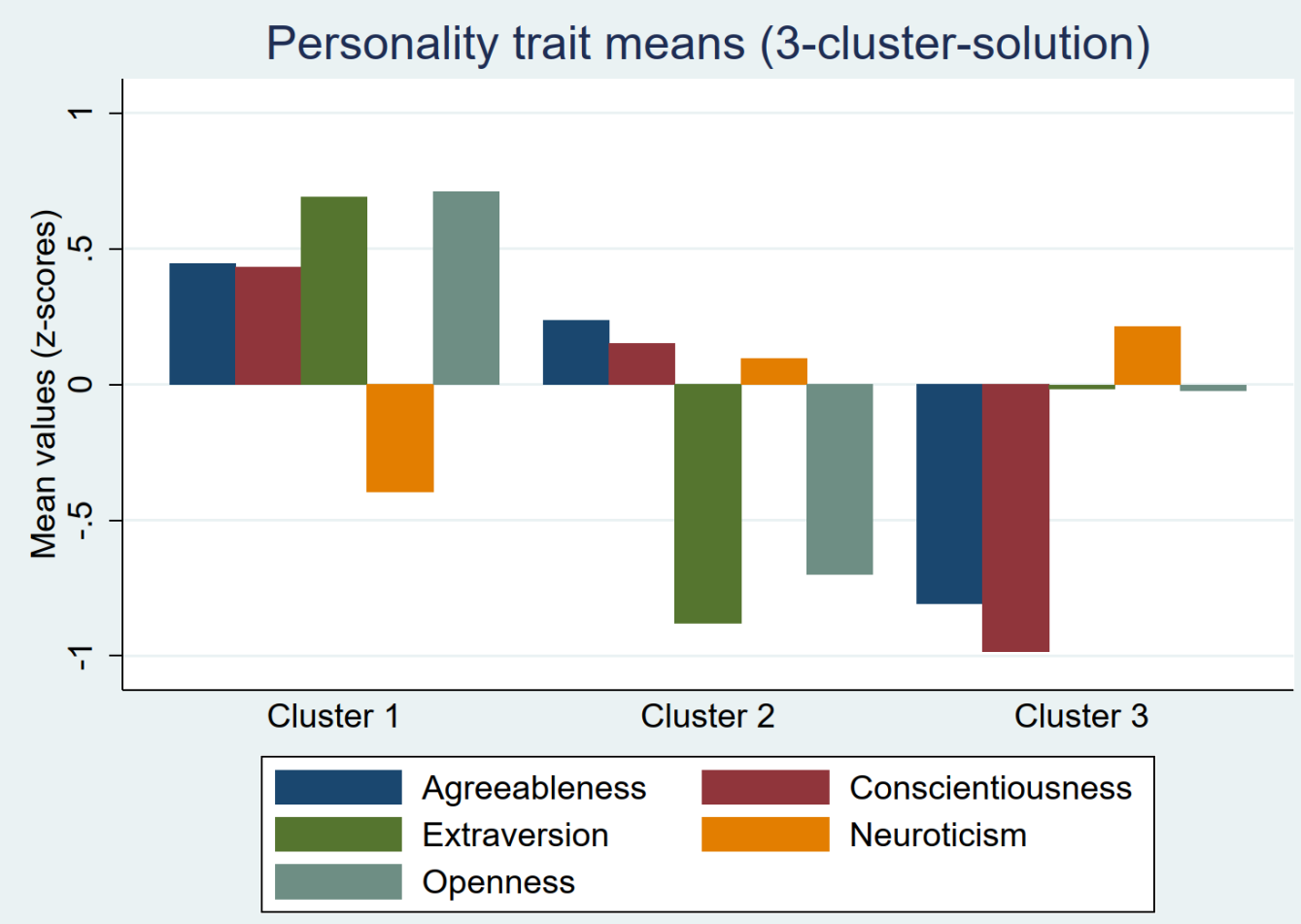


Fig. A2: Personality mean values in 4-cluster-solution

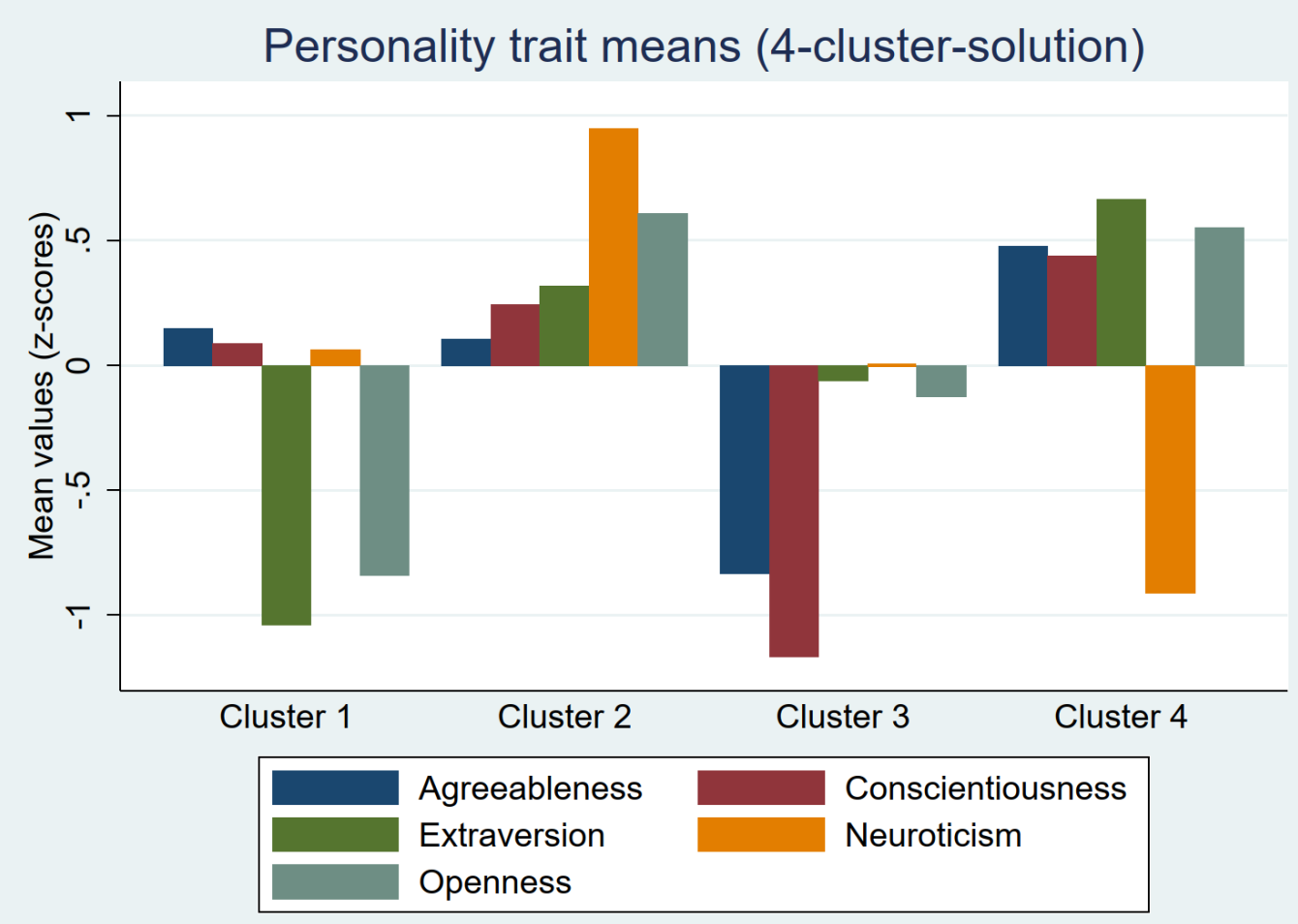


Fig. A3: Personality mean values in 5-cluster-solution

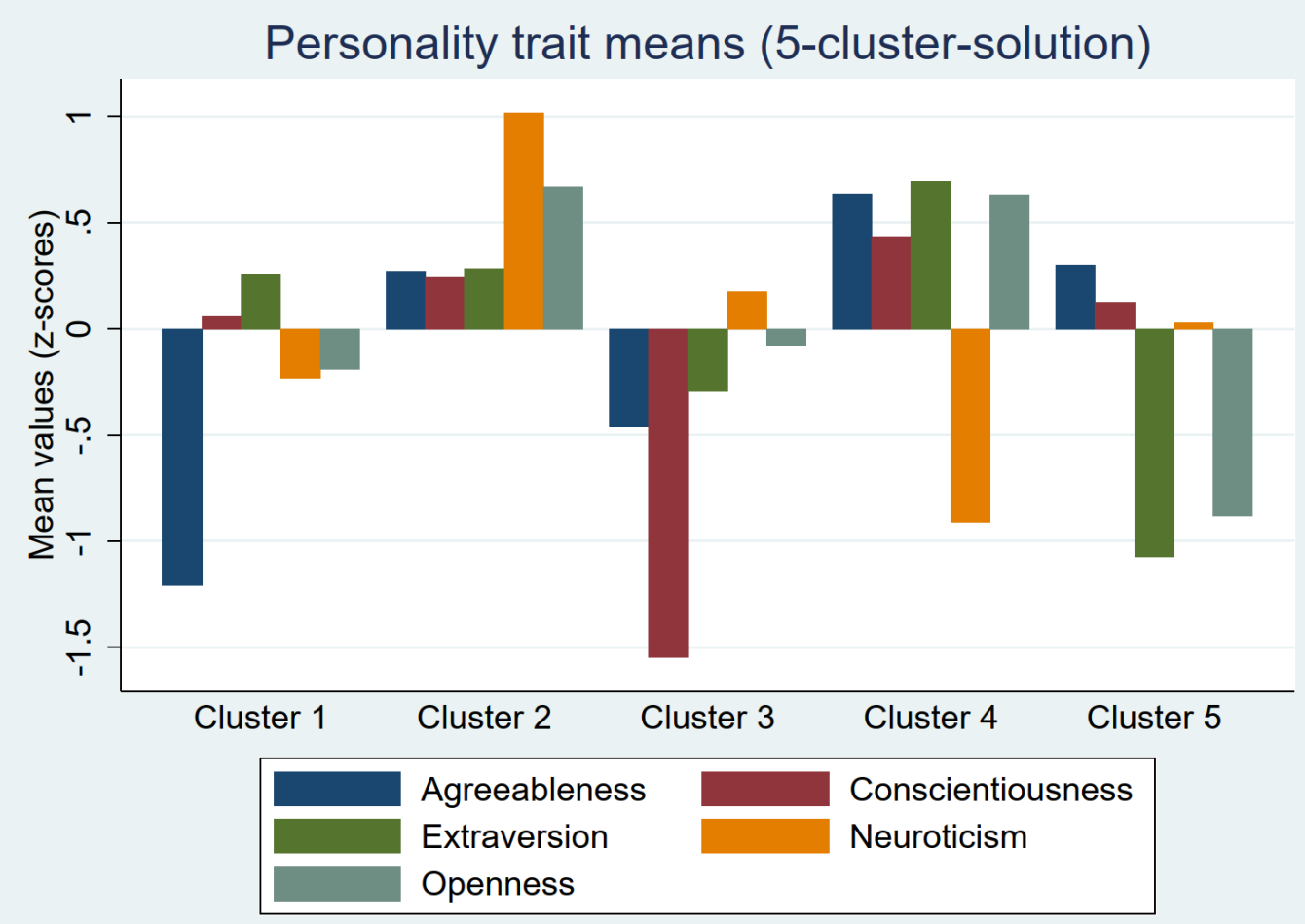


Cox-Snell (CS) residuals are plotted versus the estimated cumulative hazard function as shown in the figure below. If the Cox PH model fits the data well we would expect the Cum ulative Hazard line to follow a linear trend with a slope of 1, i.e. the estimations would follow the straight reference line (based on CS residuals) that is shown in the graph. Some variation, in particular at the right end of the tail is expected for analytical reasons (e.g. most of the events have already happened). As we can see, the Cox PH model fits the data relatively well.

Fig. A4: Cox-Snell Residuals

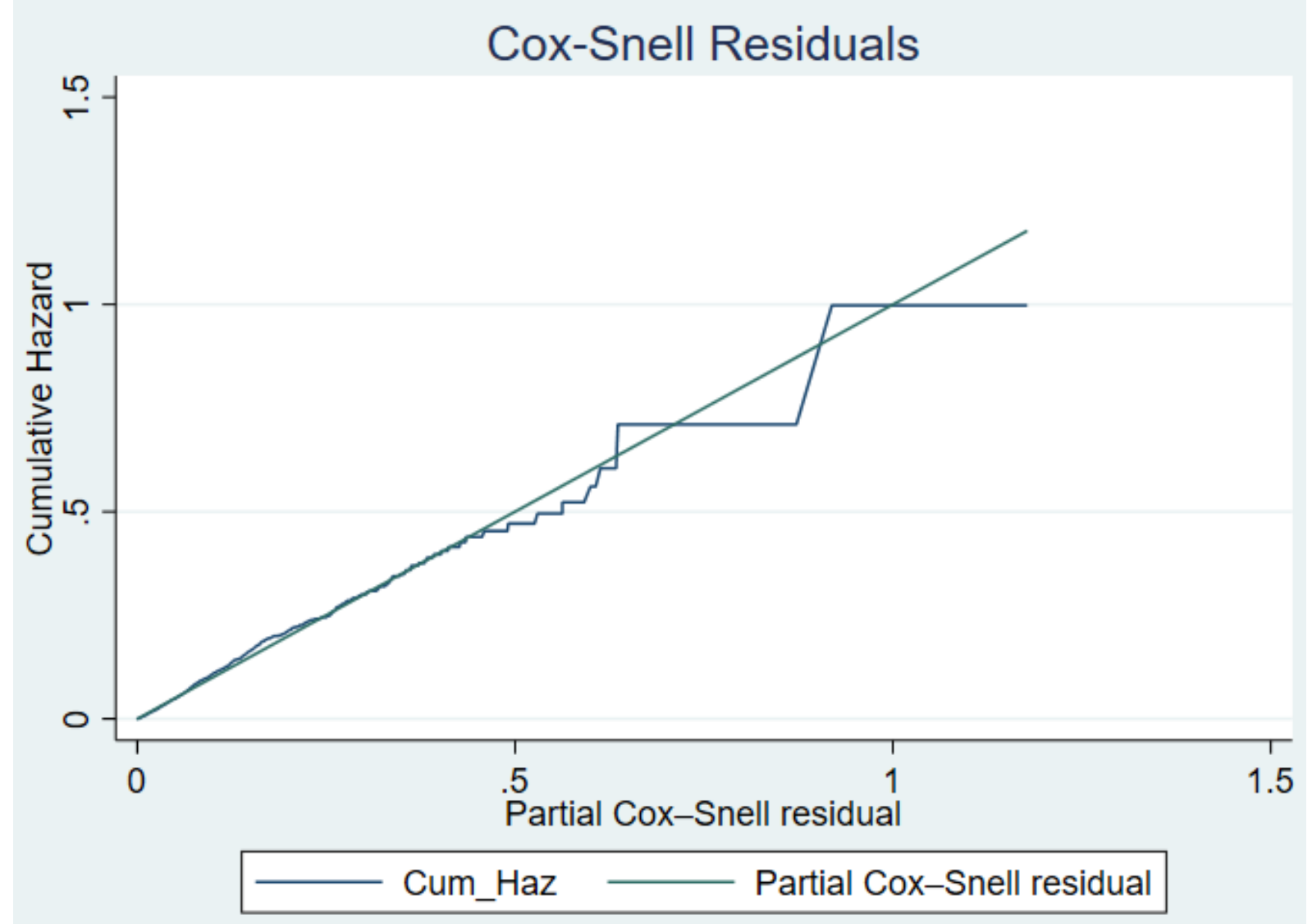


Table A1: Hazard Ratios of Childbearing (Timing of First Childbirth)

\begin{tabular}{|c|c|c|c|}
\hline \multirow{3}{*}{ Agreeableness } & Total & Females & Males \\
\hline & 1.07 & 1.04 & 1.10 \\
\hline & $(1.00 ; 1.15)$ & $(0.95 ; 1.14)$ & $(0.99 ; 1.21)$ \\
\hline \multirow[t]{2}{*}{ Conscientiousness } & 0.94 & 0.99 & 0.91 \\
\hline & $(0.88 ; 1.01)$ & $(0.90 ; 1.09)$ & $(0.82 ; 1.01)$ \\
\hline \multirow[t]{2}{*}{ Extraversion } & 1.05 & 0.98 & 1.14 \\
\hline & $(0.98 ; 1.12)$ & $(0.90 ; 1.07)$ & $(1.04 ; 1.26)$ \\
\hline \multirow[t]{2}{*}{ Neuroticism } & 0.99 & 0.96 & 1.02 \\
\hline & $(0.92 ; 1.06)$ & $(0.88 ; 1.06)$ & $(0.92 ; 1.13)$ \\
\hline \multirow[t]{2}{*}{ Openness } & 0.98 & 1.01 & 0.94 \\
\hline & $(0.91 ; 1.05)$ & $(0.92 ; 1.10)$ & $(0.84 ; 1.04)$ \\
\hline \multicolumn{4}{|l|}{ Gender (ref.: Females) } \\
\hline Males & $\begin{array}{c}0.88 \\
(0.78 ; 0.99)\end{array}$ & - & - \\
\hline Years of Education & $\begin{array}{c}1.00 \\
(0.98 ; 1.03)\end{array}$ & $\begin{array}{c}0.98 \\
(0.95 ; 1.02)\end{array}$ & $\begin{array}{c}1.01 \\
(0.97 ; 1.05)\end{array}$ \\
\hline \multicolumn{4}{|c|}{ Enrolment Status (ref.: Not Enrolled) } \\
\hline Enrolled & $\begin{array}{c}0.70 \\
(0.56 ; 0.86)\end{array}$ & $\begin{array}{c}0.53 \\
(0.40 ; 0.70)\end{array}$ & $\begin{array}{c}0.96 \\
(0.71 ; 1.31)\end{array}$ \\
\hline Birth Year & $\begin{array}{c}1.04 \\
(1.02 ; 1.06)\end{array}$ & $\begin{array}{c}1.04 \\
(1.02 ; 1.07)\end{array}$ & $\begin{array}{c}1.04 \\
(1.01 ; 1.06)\end{array}$ \\
\hline \multicolumn{4}{|l|}{ Civil Status (ref.: Single) } \\
\hline Cohabited & $\begin{array}{c}7.87 \\
(6.02 ; 10.27)\end{array}$ & $\begin{array}{c}5.53 \\
(4.04 ; 7.57)\end{array}$ & $\begin{array}{c}12.51 \\
(7.83 ; 19.99)\end{array}$ \\
\hline Married & $\begin{array}{c}25.70 \\
(19.69 ; 33.54)\end{array}$ & $\begin{array}{c}16.23 \\
(11.94 ; 22.07)\end{array}$ & $\begin{array}{c}45.58 \\
(28.53 ; 72.81)\end{array}$ \\
\hline Divorced/Widowed & $\begin{array}{c}3.00 \\
(1.17 ; 7.67)\end{array}$ & $\begin{array}{c}2.53 \\
(0.74 ; 8.64)\end{array}$ & $\begin{array}{c}3.72 \\
(0.86 ; 16.13)\end{array}$ \\
\hline Income (log) & $\begin{array}{c}1.19 \\
(1.07 ; 1.33)\end{array}$ & $\begin{array}{c}1.07 \\
(0.94 ; 1.22)\end{array}$ & $\begin{array}{c}1.34 \\
(1.15 ; 1.56)\end{array}$ \\
\hline \multicolumn{4}{|c|}{ Maternal Education (ref.: Secondary Degree) } \\
\hline No Degree & $\begin{array}{c}0.87 \\
(0.54 ; 1.39)\end{array}$ & $\begin{array}{c}0.94 \\
(0.52 ; 1.71)\end{array}$ & $\begin{array}{c}0.98 \\
(0.49 ; 1.94)\end{array}$ \\
\hline Intermediate Degree & $\begin{array}{c}1.05 \\
(0.89 ; 1.25)\end{array}$ & $\begin{array}{c}1.02 \\
(0.80 ; 1.29)\end{array}$ & $\begin{array}{c}1.14 \\
(0.89 ; 1.46)\end{array}$ \\
\hline Upper Secondary Degree & $\begin{array}{c}1.11 \\
(0.88 ; 1.40)\end{array}$ & $\begin{array}{c}1.10 \\
(0.81 ; 1.49)\end{array}$ & $\begin{array}{c}1.19 \\
(0.84 ; 1.68)\end{array}$ \\
\hline Other & $\begin{array}{c}1.54 \\
(0.98 ; 2.42)\end{array}$ & $\begin{array}{c}1.06 \\
(0.56 ; 2.04)\end{array}$ & $\begin{array}{c}2.43 \\
(1.40 ; 4.21)\end{array}$ \\
\hline
\end{tabular}

Paternal Education (ref.: Secondary Degree)

$\begin{array}{lccc}\text { No Degree } & 1.75 & 2.54 & 1.13 \\ \text { Intermediate Degree } & (1.04 ; 2.96) & (1.34 ; 4.82) & (0.58 ; 2.24) \\ & 1.13 & 1.15 & 1.11 \\ \text { Upper Secondary Degree } & (0.94 ; 1.35) & (0.90 ; 1.46) & (0.86 ; 1.44) \\ & (0.92 ; 1.34) & (0.98 ; 1.66) & (0.68 ; 1.24) \\ \text { Other } & 0.95 & 1.08 & 0.79 \\ & (0.60 ; 1.50) & (0.57 ; 2.05) & (0.42 ; 1.49)\end{array}$

Region (ref.: West)

East

1.53

(1.25; 1.86)
1.61

(1.28; 2.03)
1.44

$(1.11 ; 1.86)$ 
Table A2: Hazard Ratios of Childbearing (Timing of Second Childbirth)

\begin{tabular}{|c|c|c|c|}
\hline \multirow[b]{2}{*}{ Agreeableness } & Total & Females & Males \\
\hline & $\begin{array}{c}1.05 \\
0.97 \cdot 1\end{array}$ & $\begin{array}{c}0.97 \\
(0.87 \cdot 109)\end{array}$ & $\begin{array}{c}1.15 \\
(102 \cdot 129)\end{array}$ \\
\hline Conscientiousness & $\begin{array}{c}0.94 \\
(0.87 ; 1.02)\end{array}$ & $\begin{array}{c}0.87 \\
(0.78 ; 0.98)\end{array}$ & $\begin{array}{c}0.99 \\
(0.89 ; 1.11)\end{array}$ \\
\hline Extraversion & $\begin{array}{c}0.90 \\
(0.83 ; 0.97)\end{array}$ & $\begin{array}{c}0.92 \\
(0.83 ; 1.03)\end{array}$ & $\begin{array}{c}0.85 \\
(0.75 ; 0.96)\end{array}$ \\
\hline Neuroticism & $\begin{array}{c}0.95 \\
(0.87 ; 1.03)\end{array}$ & $\begin{array}{c}0.90 \\
(0.81 ; 1.01)\end{array}$ & $\begin{array}{c}0.98 \\
(0.87 ; 1.11)\end{array}$ \\
\hline Openness & $\begin{array}{c}1.02 \\
(0.94 ; 1.11)\end{array}$ & $\begin{array}{c}1.07 \\
(0.95 ; 1.21)\end{array}$ & $\begin{array}{c}1.02 \\
(0.90 ; 1.14)\end{array}$ \\
\hline Males & $\begin{array}{c}1.27 \\
(1.09 ; 1.48)\end{array}$ & - & - \\
\hline Years of Education & $\begin{array}{c}1.10 \\
(1.06 ; 1.13)\end{array}$ & $\begin{array}{c}1.12 \\
(1.07 ; 1.18)\end{array}$ & $\begin{array}{c}1.07 \\
(1.02 ; 1.12)\end{array}$ \\
\hline \multicolumn{4}{|c|}{ Enrolment Status (ref.: Not Enrolled) } \\
\hline Enrolled & $\begin{array}{c}0.87 \\
(0.61 ; 1.23)\end{array}$ & $\begin{array}{c}0.81 \\
(0.51 ; 1.29)\end{array}$ & $\begin{array}{c}0.93 \\
(0.56 ; 1.55)\end{array}$ \\
\hline Birth Year & $\begin{array}{c}1.07 \\
(1.04 ; 1.09)\end{array}$ & $\begin{array}{c}1.07 \\
(1.04 ; 1.11)\end{array}$ & $\begin{array}{c}1.06 \\
(1.03 ; 1.10)\end{array}$ \\
\hline \multicolumn{4}{|l|}{ Civil Status (ref.: Single) } \\
\hline Cohabited & $\begin{array}{c}5.11 \\
(2.64 ; 9.91)\end{array}$ & $\begin{array}{c}6.78 \\
(3.18 ; 14.45)\end{array}$ & $\begin{array}{c}3.14 \\
(0.94 ; 10.46)\end{array}$ \\
\hline Married & $\begin{array}{c}7.23 \\
(3.84 ; 13.62)\end{array}$ & $\begin{array}{c}7.89 \\
(3.79 ; 16.42)\end{array}$ & $\begin{array}{c}5.57 \\
(1.72 ; 18.01)\end{array}$ \\
\hline Divorced/Widowed & $\begin{array}{c}1.85 \\
(0.59 ; 5.80)\end{array}$ & $\begin{array}{c}1.92 \\
(0.47 ; 7.83)\end{array}$ & $\begin{array}{c}2.42 \\
(0.35 ; 16.52)\end{array}$ \\
\hline Income (log) & $\begin{array}{c}1.05 \\
(0.96 ; 1.14)\end{array}$ & $\begin{array}{c}0.94 \\
(0.85 ; 1.05)\end{array}$ & $\begin{array}{c}1.25 \\
(1.05 ; 1.48)\end{array}$ \\
\hline \multicolumn{4}{|c|}{ Maternal Education (ref.: Secondary Degree) } \\
\hline No Degree & $\begin{array}{c}1.50 \\
(1.01 ; 2.25)\end{array}$ & $\begin{array}{c}1.04 \\
(0.49 ; 2.19)\end{array}$ & $\begin{array}{c}1.71 \\
(1.04 ; 2.80)\end{array}$ \\
\hline Intermediate Degree & $\begin{array}{c}1.07 \\
(0.87 ; 1.33)\end{array}$ & $\begin{array}{c}0.97 \\
(0.73 ; 1.30)\end{array}$ & $\begin{array}{c}1.21 \\
(0.90 ; 1.61)\end{array}$ \\
\hline Upper Secondary Degree & $\begin{array}{c}1.17 \\
(0.88 ; 1.54)\end{array}$ & $\begin{array}{c}0.98 \\
(0.68 ; 1.42)\end{array}$ & $\begin{array}{c}1.36 \\
(0.90 ; 2.07)\end{array}$ \\
\hline Other & $\begin{array}{c}1.28 \\
(0.77 ; 2.14)\end{array}$ & $\begin{array}{c}1.42 \\
(0.62 ; 3.25)\end{array}$ & $\begin{array}{c}1.22 \\
(0.65 ; 2.28)\end{array}$ \\
\hline \multicolumn{4}{|c|}{ Paternal Education (ref.: Secondary Degree) } \\
\hline No Degree & $\begin{array}{c}0.85 \\
(0.53 ; 1.36)\end{array}$ & $\begin{array}{c}0.92 \\
(0.40 ; 2.11)\end{array}$ & $\begin{array}{c}0.86 \\
(0.50 ; 1.47)\end{array}$ \\
\hline Intermediate Degree & $\begin{array}{c}1.07 \\
(0.86 ; 1.32)\end{array}$ & $\begin{array}{c}0.91 \\
(0.67 ; 1.22)\end{array}$ & $\begin{array}{c}1.23 \\
(0.91 ; 1.67)\end{array}$ \\
\hline Upper Secondary Degree & $\begin{array}{c}0.98 \\
(0.77 ; 1.26)\end{array}$ & $\begin{array}{c}0.98 \\
(0.70 ; 1.38)\end{array}$ & $\begin{array}{c}0.92 \\
(0.63 ; 1.33)\end{array}$ \\
\hline Other & $\begin{array}{c}1.05 \\
(0.63 ; 1.75)\end{array}$ & $\begin{array}{c}0.85 \\
(0.36 ; 2.03)\end{array}$ & $\begin{array}{c}1.05 \\
(0.58 ; 1.92)\end{array}$ \\
\hline \multicolumn{4}{|l|}{ Region (ref.: West) } \\
\hline East & $\begin{array}{c}0.71 \\
(0.57 ; 0.90)\end{array}$ & $\begin{array}{c}0.84 \\
(0.65 ; 1.10)\end{array}$ & $\begin{array}{c}0.64 \\
(0.47 ; 0.86)\end{array}$ \\
\hline $\mathbf{N}$ & 11,508 & 6,570 & 4,938 \\
\hline
\end{tabular}


Fig. A5: Hazard Ratios Agreeableness - Childbearing (Mediation Analyses)

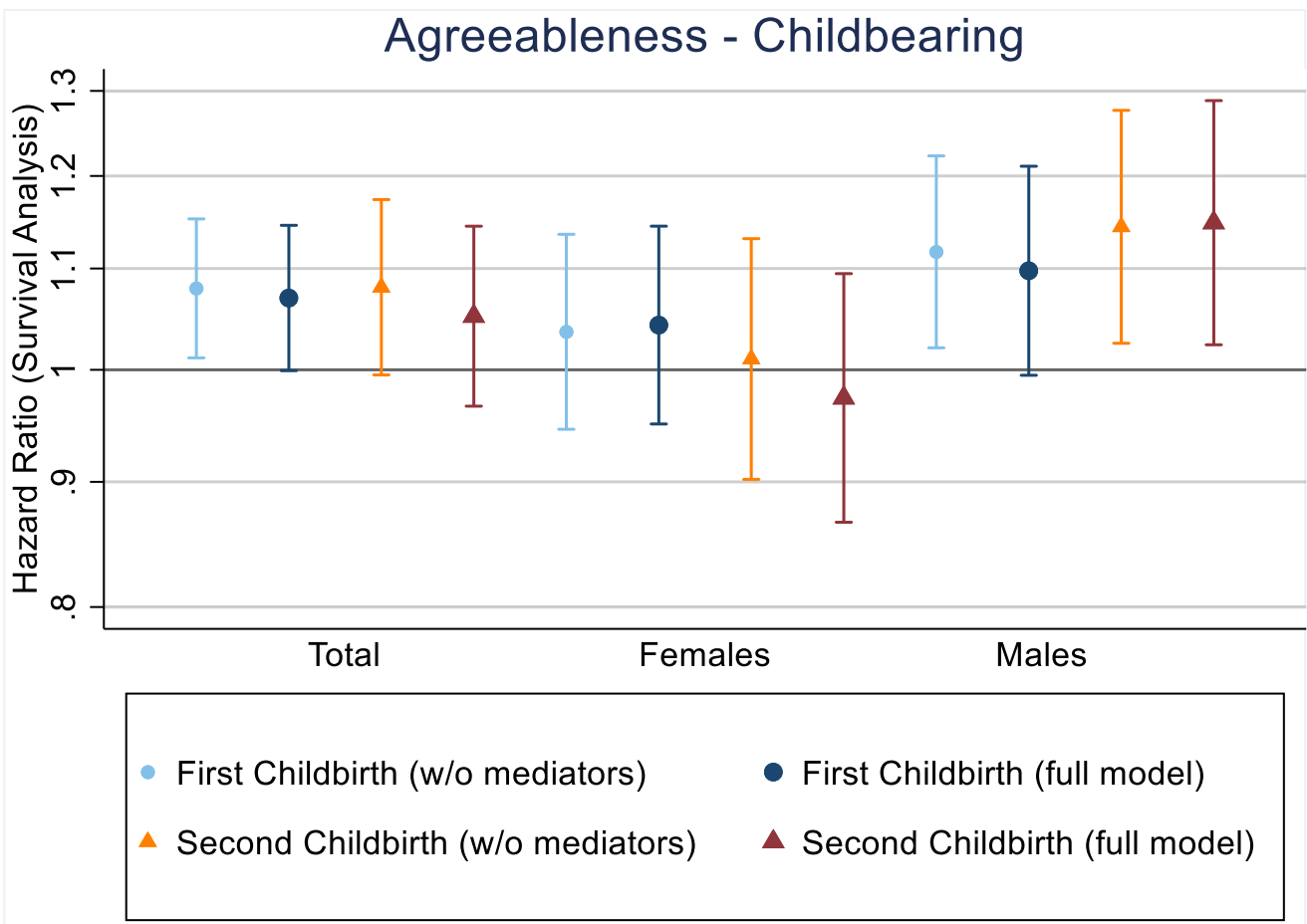

Note: Models w/o mediators controlled for: gender (total sample), birth year, region, parental education;

Full models also controlled for: civil status, income, education (years and enrolment status) 
Fig. A6: Hazard Ratios Conscientiousness - Childbearing (Mediation Analyses)

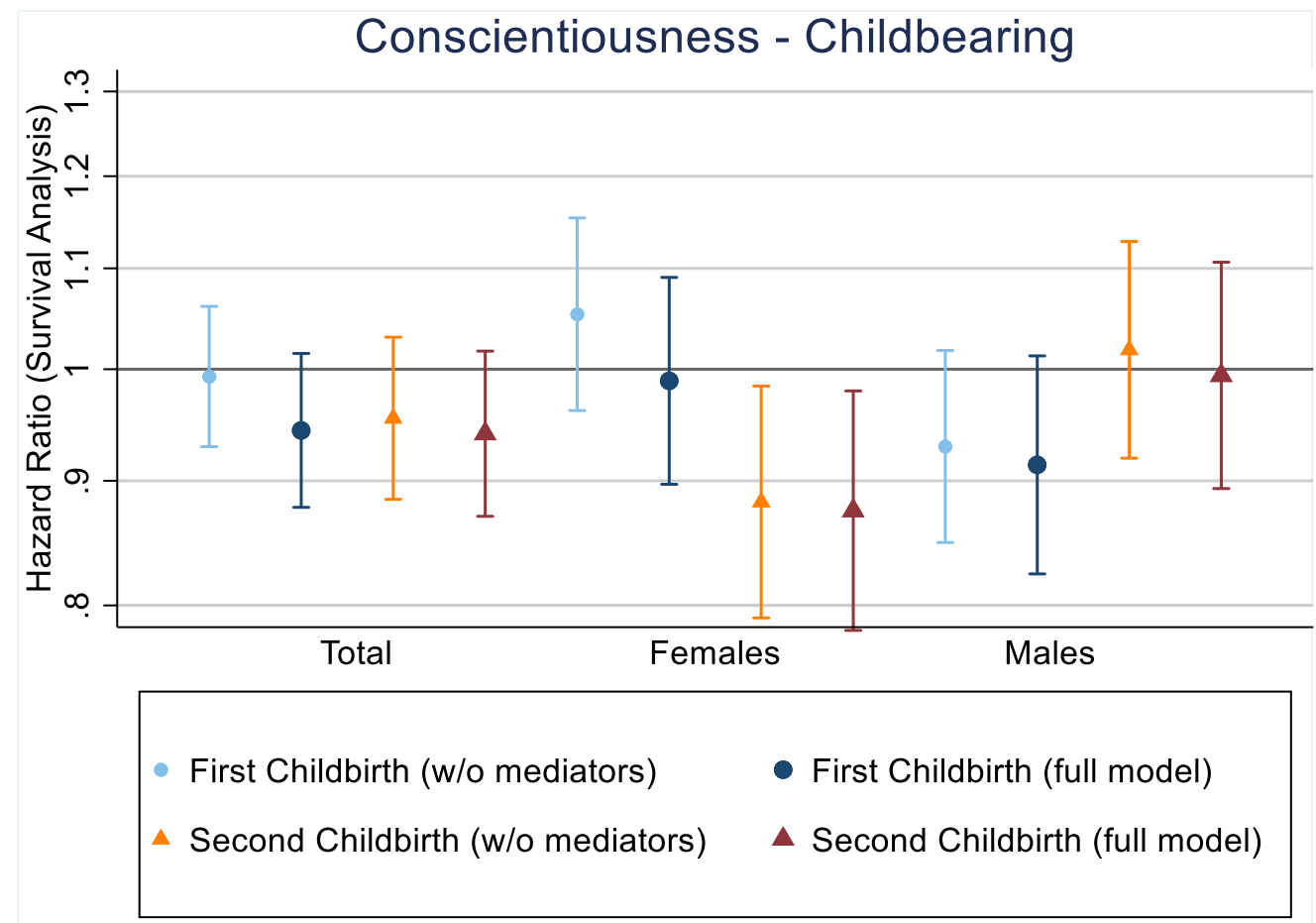

Note: Models w/o mediators controlled for: gender (total sample), birth year, region, parental education;

Full models also controlled for: civil status, income, education (years and enrolment status) 
Fig. A7: Hazard Ratios Extraversion - Childbearing (Mediation Analyses)

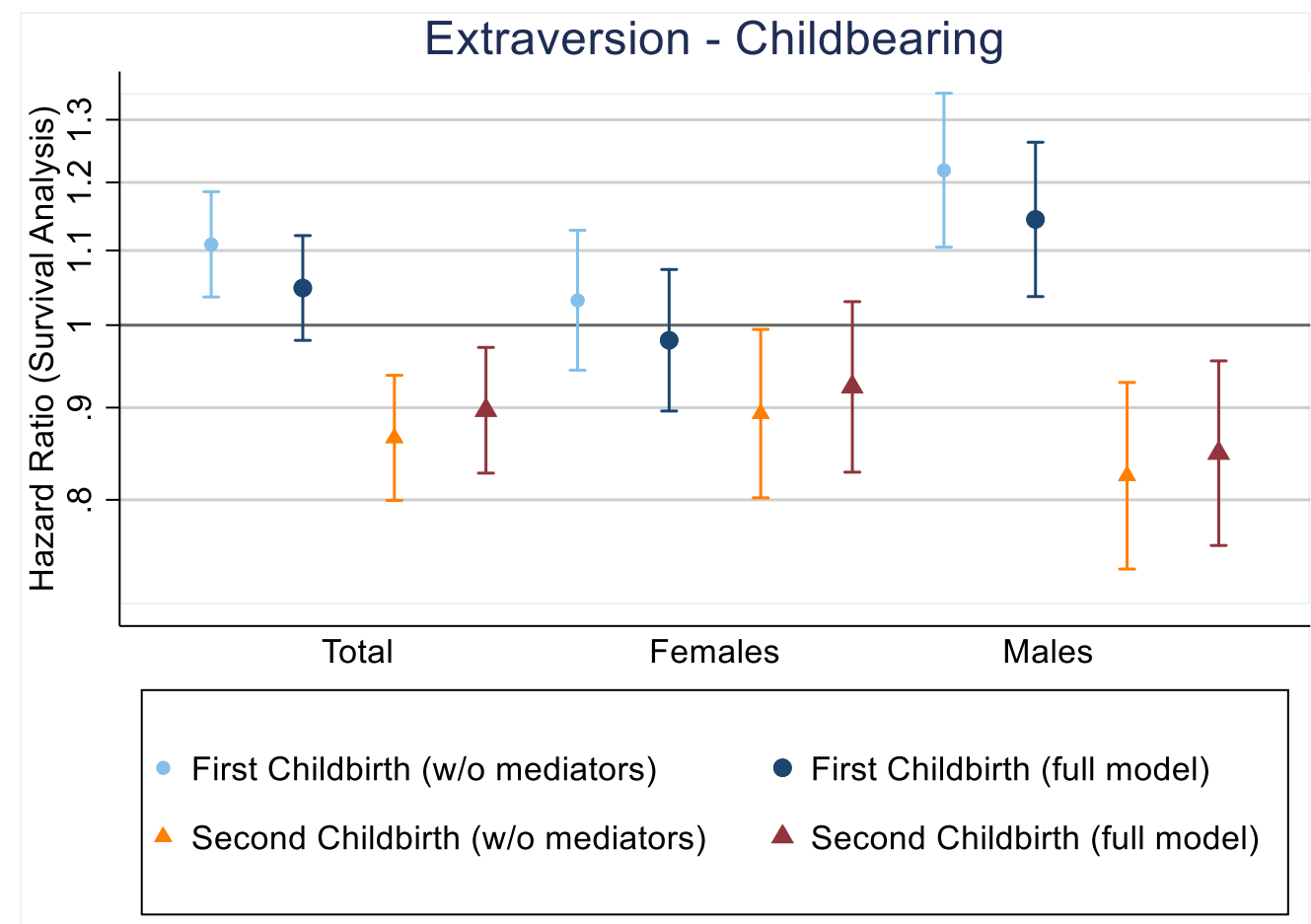

Note: Models w/o mediators controlled for: gender (total sample), birth year, region, parental education;

Full models also controlled for: civil status, income, education (years and enrolment status) 
Fig. A8: Hazard Ratios Neuroticism - Childbearing (Mediation Analyses)

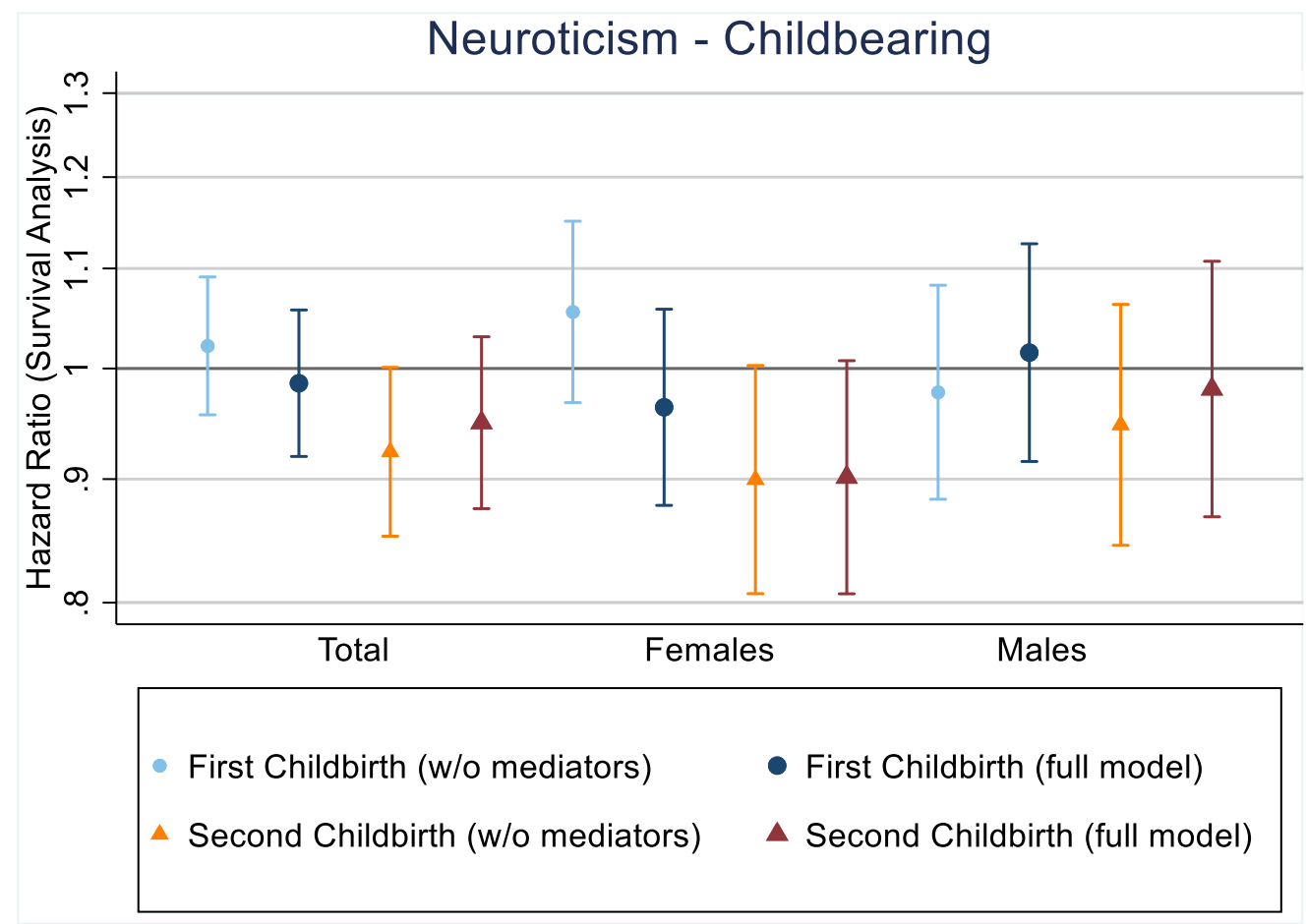

Note: Models w/o mediators controlled for: gender (total sample), birth year, region, parental education;

Full models also controlled for: civil status, income, education (years and enrolment status) 
Table A3: Hazard Ratios of Childbearing (First Childbirth, using Personality Clusters)

3-cluster solution

Personality Cluster (ref.: 1)

2

3

4-cluster solution

Personality Cluster (ref.: 1)

2

3

4

5-cluster solution

Personality Cluster (ref.: 1)

2

3

4

5

$\mathbf{N}$
Total

\section{Females}

Males

$\begin{array}{ccc}0.93 & 0.94 & 0.90 \\ (0.79 ; 1.08) & (0.76 ; 1.16) & (0.71 ; 1.14) \\ 1.01 & 0.99 & 1.03 \\ (0.86 ; 1.18) & (0.81 ; 1.21) & (0.82 ; 1.28)\end{array}$

1.04

0.97

$(0.86 ; 1.24)$

0.99

(0.76; 1.25)

0.93

(0.83; 1.19)

$(0.74 ; 1.17)$

0.94

0.95

$(0.74 ; 1.20)$

(0.79; 1.13)

1.11

0.98

$(0.91 ; 1.36)$

1.18

(0.74; 1.30)

0.95

(0.95; 1.46)

1.06

(0.70; 1.28)

0.92

(0.86; 1.29)

1.15

(0.69; 1.23)

0.99

(0.76; 1.29)

(0.93; 1.41)

11,865

25,953
1.09

(0.86; 1.39)

1.11

$(0.82 ; 1.51)$

0.95

(0.73; 1.23)

Note: All models controlled for gender (total samples only), birth year, region, parental education, civil status, income, education (years and enrolment status) 
Table A4: Hazard Ratios of Childbearing (Second Childbirth, using Personality Clusters)

\section{Total Females Males}

3-cluster solution

Personality Cluster (ref.: 1)

2

$\begin{array}{lll}1.03 & 1.03 & 1.02\end{array}$

3

$(0.86 ; 1.25) \quad(0.80 ; 1.33) \quad(0.76 ; 1.35)$

$1.01 \quad 1.04$

$(0.84 ; 1.21) \quad(0.79 ; 1.37) \quad(0.79 ; 1.26)$

4-cluster solution

Personality Cluster (ref.: 1)

2

1.11

0.96

1.24

(0.89; 1.39)

(0.68; 1.35)

0.93

(0.92; 1.68)

1.06

$(0.68 ; 1.27)$

1.17

$(0.84 ; 1.35)$

0.98

$(0.81 ; 1.69)$

1.11

$(0.70 ; 1.37)$

1.20

$(0.87 ; 1.43)$

(0.85; 1.71)

5-cluster solution

Personality Cluster (ref.: 1)

2

0.86

0.89

$(0.66 ; 1.11)$

$(0.60 ; 1.31)$

1.00

0.79

0.76

3

(0.79; 1.27)

$(0.56 ; 1.12)$

0.75

0.89

(0.52; 1.09)

$(0.69 ; 1.15)$

0.85

0.98

(0.59; 1.24)

(0.54; 1.08)

1.17

(0.83; 1.66)

0.95

5

$(0.78 ; 1.22)$

$(0.66 ; 1.37)$

$\begin{array}{lll}11,508 & 6,570 \quad 4,938\end{array}$

$\begin{array}{lll}11,508 & 6,570 & 4,938\end{array}$

$(0.75 ; 1.33)$

$\mathbf{N}$

Note: All models controlled for gender (total samples only), birth year, region, parental education, civil status, income, education (years and enrolment status) 
Table A5: Poisson Regression Models

\section{Total}

Age 40+

Agreeableness

Conscientiousness

Extraversion

Neuroticism

Openness

$\mathbf{N}$

Age 45+

Agreeableness

Conscientiousness

Extraversion

Neuroticism

Openness

$\mathbf{N}$

Age 50+

Agreeableness

Conscientiousness

Extraversion

Neuroticism

Openness

16,713

0.03

$-0.01$

0.01

$-0.01$

$-0.01$

13,736

0.03

0.01

$$
0.01
$$

$-0.01$

$-0.01$

$$
\begin{array}{ccc}
0.03 & 0.03 & 0.02 \\
(0.02 ; 0.04) & (0.02 ; 0.05) & (0.01 ; 0.04) \\
-0.01 & -0.02 & <0.01 \\
(-0.02 ;<0.01) & (-0.03 ;>-0.01) & (>-0.01 ; 0.02) \\
0.01 & 0.02 & 0.02 \\
(<0.01 ; 0.03) & (<0.01 ; 0.03) & (>-0.01 ; 0.03) \\
-0.01 & -0.01 & -0.01 \\
(-0.02 ;<0.01) & (-0.02 ; 0.01) & (-0.02 ; 0.01) \\
-0.01 & >-0.01 & -0.01 \\
(-0.02 ;<0.01) & (-0.02 ; 0.01) & (-0.03 ;<0.01)
\end{array}
$$

(0.01;0.04)

$(-0.02 ; 0.01)$

$(<0.01 ; 0.03)$

$(-0.02 ;<0.01)$

$(-0.02 ;<0.01)$

(0.01; 0.04)

$(-0.01 ; 0.02)$

(>-0.01;0.03)

$(-0.02 ;<0.01)$

$(-0.02 ; 0.01)$

\section{Females}

8,306

8,407

\section{Males}

